\title{
Emergency boarding: An integrative framework for analyzing causes and seeking solutions
}

\author{
Vincent Limoges ${ }^{1}$, Paul Gemmel ${ }^{2}$, Sylvain Landry*1,3, Peter De Paepe ${ }^{4}$ \\ ${ }^{1}$ Healthcare Management Hub, HEC Montréal, Montréal (Québec), Canada \\ ${ }^{2}$ Department of Innovation, Entrepeurship and Service Management, Faculty of Economics and Business Administration, Ghent \\ University, Belgium \\ ${ }^{3}$ Department of Logistics and Operations Management, HEC Montréal, Montréal (Québec), Canada \\ ${ }^{4}$ Emergency Department Ghent University Hospital and Faculty of Medicine and Health Sciences, Ghent University, Belgium
}

Received: October 31, 2016

DOI: $10.5430 /$ jha.v6n2p88
Accepted: March 6, 2017

Online Published: March 20, 2017

\begin{abstract}
Background: One of the root causes of crowding at the Emergency Department (ED) is boarding, i.e. the practice of holding admitted patients in the ED until an inpatient (IP) bed becomes available. Although ED boarding has been approached by various authors, few of them have aimed to see how different hospitals perform in regard to this issue.

Objective: This study will approach ED boarding from different angles, analyzing both quantitative and qualitative data, and following both deductive and inductive reasoning. The purpose is to develop a validated integrative conceptual framework which can be used to analyze ED boarding, and to look for solutions.

Methods: The development of the framework is based on an extensive literature review and a multiple case study research with both qualitative and quantitative data collection.

Results: ED boarding was found to be prominent in the studied hospitals. Four root causes of ED boarding were elucidated, which are: (1) uncoordinated admissions and discharges, (2) late discharges, (3) the inability to discharge patients, and (4) a lack of communication, collaboration, and information between the different actors of the patient care process. Many solutions are proposed to improve these issues.

Conclusions: Through the analysis of various types of data, an integrative conceptual framework for ED boarding was elaborated for analyzing causes and seeking solutions. The quantative data cannot only be used in the analysis stage, but can also help in designing a solution as there are clear recognizable trends in arrival, discharge and ED boarding time. "Communication, collaboration and information", although not explicitly discussed in the literature, was found to be the most prominent cause and solution to ED boarding in the field study.

Practice implications: Management practitioners now have a framework demonstrating probable causes for ED boarding, which provides a starting point for analysis within their establishments. Pathways to improvement are suggested as well, which will help managers to reduce ED boarding. Communication, collaboration and information are important in these improvement efforts.
\end{abstract}

Key Words: Emergency department boarding, Hospital, Emergency department, Inpatient units, Patient flow

*Correspondence: Sylvain Landry; Email: sylvain.landry@hec.ca; Address: Healthcare Management Hub and Department of Logistics and Operations Management, HEC Montréal, Canada. 


\section{INTRODUCTION}

Emergency department (ED) overcrowding has been a threat to public health for numerous years, and continues to cause various deleterious effects on both patients and those involved in the process of care. ${ }^{[1]}$ This issue has been discussed extensively in regards to EDs across the United States, ${ }^{[2]}$ but the problem manifests itself worldwide. ${ }^{[3]}$ Causes of the ED crowding are multifactorial, ${ }^{[4]}$ and are often interrelated. The patient flow process is composed of smaller processes that are intertwined to form a global patient care stream, which means that any delays or issues relative to one of the parts affects its entirety.

One of the root causes of ED crowding is ED boarding. ${ }^{[5]}$ As Asplin et al. wrote, it "may be the most important [area] for immediate research and operational strategies to alleviate ED crowding". ${ }^{6]}$ ED boarding has been defined in a variety of ways according to the goals of the authors employing the term. The most common definition is the following: "The practice of holding admitted patients in the ED until an inpatient (IP) bed becomes available [is] commonly called

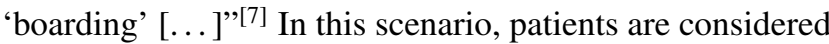
"boarders" as soon as their admission is requested by the ED physician, and are categorized as such until they arrive to their intended IP bed. This is the definition that will be used in the context of this study.

As one of the root causes of ED crowding, it has been associated with the various deleterious effects that this issue produces for patients, such as delay of care, ${ }^{[8]}$ patient safety and quality of care issues, ${ }^{[9]}$ and increased mortality, ${ }^{[10]}$ to name a few. As Falvo et al. wrote, "Until IP beds are assigned and the patients can be safely transferred, the ED staff must 'board' those patients in ED treatment beds and provide IP nursing services. Boarding IPs consume ED resources, prolongs the time all patients wait for medical attention, and reduces the number of ED treatment beds available to accommodate sudden surges in demand." ${ }^{[11]}$ It is because of its important role in causing the ED crowding and hindering patient care that ED boarding needs to be addressed more extensively.

Although ED boarding has been approached by various authors, few of them have aimed to see how different hospitals perform in regards to this issue. This study will approach the subject from different angles, analyzing both quantitative and qualitative data, and following both deductive and inductive reasoning. The purpose is to develop a validated integrative conceptual framework which can be used to analyze ED boarding, and to look for solutions. The development of the framework is based on an extensive literature review and multiple case study research.

\section{CONCEPTUAL FRAMEWORK}

With the knowledge gained through an extensive literature review of over 110 articles spanning a period of over 20 years, an initial conceptual framework was established that allows for a better understanding of the root causes and possible solutions to ED boarding. The articles were obtained from various medical and hospital management journals so as to acquire a global viewpoint from both a clinical and a managerial perspective. We do not report on this extensive literature review in this paper, but refer the reader to systematic literature reviews (e.g. Chan et al. $)^{[12]}$ and to the discussion section where we included relevant studies supporting the empirical findings.

ED boarding is an important cause of ED overcrowding, and the conceptual framework was constructed to demonstrate how these two issues are interrelated, progressively narrowing in scope towards the particular portion of the hospitalization process that includes emergency boarding. The conceptual framework (see Figure 1) included 12 causes of the ED crowding structured according to the input-throughputoutput model of Asplin et al., ${ }^{[6]} 8$ effects caused by these different factors, and finally 4 solutions to ED boarding.

\section{Methods}

\subsection{Study design}

The conceptual framework was used to analyze the issue of ED boarding within the context of three hospitals located in the province of Quebec (Canada) in order to answer three research questions:

- What are the root causes of ED boarding within hospitals?

- To what extent are these causes similar or different in varying environments?

- How can we improve the process in order to reduce the amount of boarding required?

In order to answer these research questions, a multiple case study approach was undertaken. This methodology was chosen according to the guidelines put forth by Yin. ${ }^{[13]}$

The study was approved by the research ethics committee. Each participant was asked to give his/her explicit consent for the recording of the interview, and will have the possibility of interrupting the recording at any point in time.

\subsection{Study population}

Based on the willingness and ability of hospitals to participate, three cases were chosen to corroborate the information acquired from the literature. Each hospital operates within a particular context that differs from the two others, which is 
beneficial for this research, as one of the three research questions pertains to the root causes of ED boarding in different environments. The participating hospitals are distributed as follows:

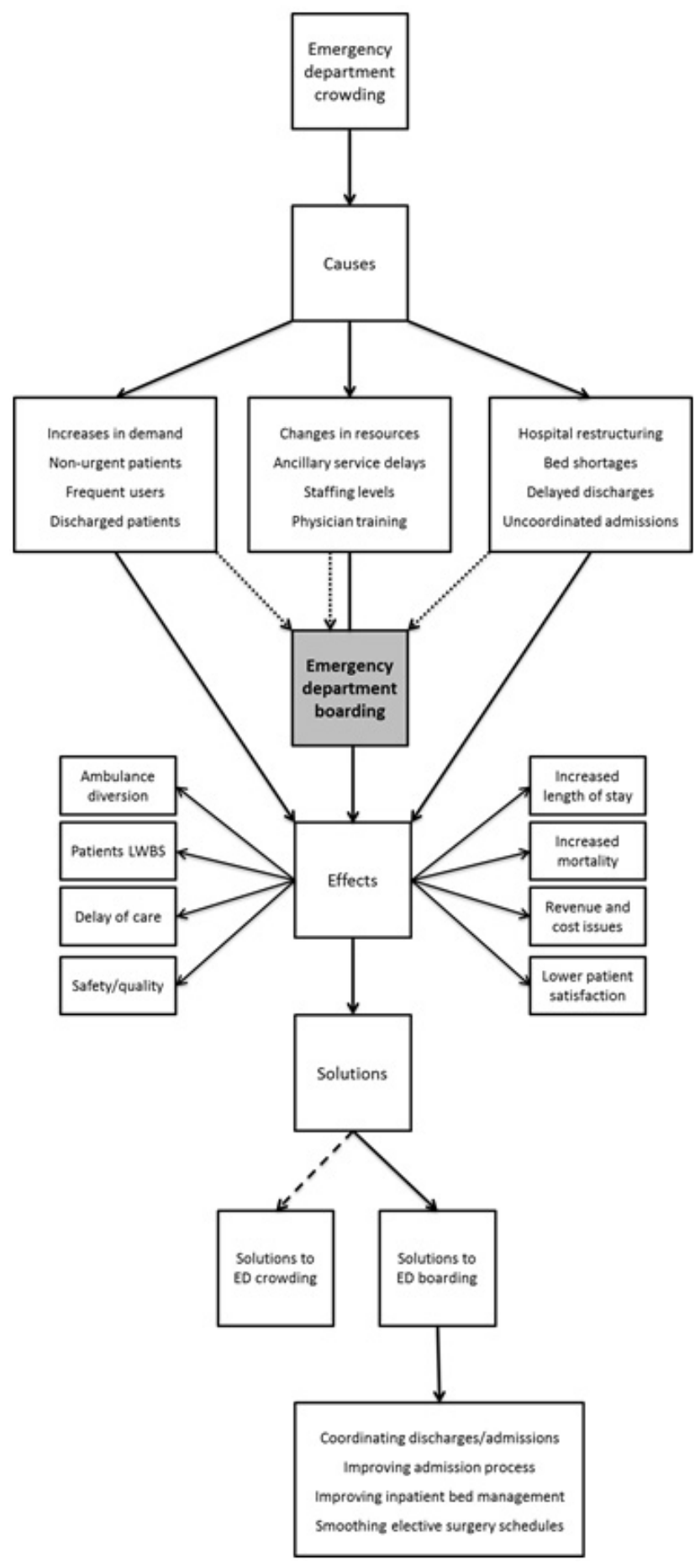

Figure 1. Initial conceptual framework displaying the causes and solutions of ED boarding based on an extensive literature review

1. Hospital A: Large (approx. 550 IP beds) urban hospital;
2. Hospital B: Small (approx. 200 IP beds) urban hospital; and

3. Hospital C: Small (approx. 250 IP beds) regional hospital.

Twenty-five actors were each met with individually for a semi-structured interview, having few set questions and using mainly probing questions in order to obtain accurate information as to the issues causing ED boarding and their possible solutions. These participants were distributed according to titles and type, including $13 \mathrm{ED}$ administrators/managers (heads of the ED, heads of the IP care unit, bed management coordinator) and 12 clinical/support employees (assistant head nurses (AHNs), nurses, social worker).

\subsection{Study protocol}

A qualitative interview guide, a consent form, and a sociodemographic data sheet were elaborated prior to the interviews. The interviews were semi-structured. The interview sought to validate whether the possible causes of ED boarding elucidated in the conceptual framework were present within the participating hospitals. Ultimately, the interviewees were asked to emphasize 4 key issues causing ED boarding out of everything that they had mentioned, and possible solutions that could improve ED boarding times.

Once the hospitals were chosen, multiple sources of data were exploited in order to thoroughly analyze the issue of ED boarding within the case studies: interviews and direct observation were planned, quantitative data regarding patient flow was obtained, and official documents were consulted. A one-day direct observation was also conducted to understand the reality of each hospital.

Quantitative information was obtained regarding the date and time of every admission request completed, as well as the date and time of every subsequent patient arrival to IP care units for 2013. With this data, it was possible to calculate average boarding times according to various metrics such as the season, the month, the day of the week and the time of day on an hourly basis.

\subsection{Data analysis}

The quantitative data was analyzed by using a generalized linear model in SAS Software v.9.3. using the general linear model (GENMOD) procedure. The dependent variable, boarding time (measured in minutes) was compared with the various independent variables seasons, months, days of the week, and the time of day. Seasons, months, and days of the week were modeled as categorical independent variables, and a reference point was chosen for each as a baseline; respectively, Winter, January, and Monday. In other words, all other variables within their respective categories were weighted 
against these reference points to compare their impact on boarding time. The time of day was modeled as a continuous independent variable, and as such, no reference point within this variable type was required. All four independent variables were also weighted globally to understand whether or not they had a significant impact on boarding time. Scaled Deviance was 1.0025 for Hospital A, 1.0042 for Hospital B, 1.0042 for Hospital C, and 1.0012 for the combined analysis of all three hospitals, which means that the model was an excellent fit, and that the data is sound. Data was established as statistically significant if the Wald 95\% Confidence Limits did not include 0 within their boundaries and if $p<.05$.

Within the qualitative interviews, participants were asked to elucidate 4 key issues that may cause ED boarding within their respective institutions. When possible, the problems that they mentioned were categorized within the 12 causes found within the literature. When their answers were unrelated or too different from the 12 proposed categories, a new category was created. Since this study also follows inductive reasoning, additional categories were expected. Ultimately, the additional categories created were as follows: (1) unbalanced surgical schedule; (2) specific patient needs (e.g. telemetry); (3) specific patient dispositions related to hospital-acquired infections (e.g. vancomycin-resistant enterococci [VRE]); (4) inability to discharge patients and (5) lack of communication/collaboration/information. The qualitative data was segmented according to the hospital, categorized employee titles, and employment categories (administration or clinical/support) in order to understand the causes of ED boarding within different institutions and according to different actors. When possible, quantitative data was interpreted to validate the answers obtained within the qualitative interviews.

Data was also collected from the qualitative interviews as to potential solutions to ED boarding. Participants were encouraged to propose as many solutions or improvements as they could think of regarding the causes they had elucidated or other problems that they thought needed attention. The data was compiled and segmented by hospital, categorized by employee titles, and employment categories, as it had been for the potential causes. Many of the proposed solutions did not fit within the categories created from the literature review, and as such, 5 more categories were created: (1) improving communication/collaboration/information, (2) improving resource management, (3) improving infectious disease management, (4) preparing patient discharge more extensively, and (5) improving external resources. As with the potential causes, potential solutions were corroborated with quantitative data when available.

\section{Results}

\subsection{Quantitative results 4.1.1 Hospital $A$}

Spring was the season within which most admissions were requested $(26.60 \%)$, while Winter saw the least admission requests $(23.75 \%)$. The season with the poorest performance in terms of average boarding time was Winter (1,291.04 minutes), while Spring had the lowest average boarding time of all seasons (822.28 minutes) (see Figure 2). Seasons were found to be statistically significant in affecting boarding times $(p=.0001)$.

May was the month within which most admissions were requested $(8.99 \%)$, while February saw the least admission requests $(7.55 \%)$. The month with the poorest performance in terms of average boarding time was January $(1,454.47 \mathrm{~min}$ utes), while May had the lowest average boarding time of all months (723.39 minutes) (see Figure 3). Months were found to be statistically significant in affecting boarding times $(p \leq .0001)$.

Tuesday was the day of the week within which most admissions were requested (15.95\%), while Sunday saw the least admission requests (13.32\%). The day of the week with the poorest performance in terms of average boarding time was Friday (1,138.31 minutes), while Monday had the lowest average boarding time of all days of the week (967.36 minutes) (see Figure 4). Finally, Friday saw the most discharges (20.75\%), while Sunday had the least (6.85\%) (see Figure 5). Days of the week were not found to be statistically significant in affecting boarding times $(p=.0720)$.

16:00-16:59 was the hour within which most admissions were requested (8.85\%), while 05:00-05:59 saw the least admission requests $(0.71 \%)$. The hour with the poorest performance in terms of average boarding time was 11:0011:59 (1,200.24 minutes), while 06:00-06:59 had the lowest average boarding time of all hours (799.13 minutes) (see Figure 6). Finally, 14:00-14:59 had the most discharges $(11.97 \%$ ), while 06:00-06:59 had the least (0.20\%) (see Figure 7). Hours were not found to be statistically significant in affecting boarding times $(p=.1299)$.

$53.5 \%$ of admissions were requested between 08:00 and 15:59, the period within which the hospital has the most personnel. $46.5 \%$ of admissions were requested outside of this period. There was an important peak between 10:00 and $13: 59$, wherein $31.79 \%$ of admissions were requested. $30.70 \%$ of arrivals occurred between 08:00 and 15:59. 65.3\% of patients arrived to their IP beds outside of this period, and there was an important peak between 20:00 and 23:59, wherein $25.05 \%$ of arrivals occurred. $65.23 \%$ of discharges happened between 08:00 and 15:59. 34.77\% percent of dis- 
charges occurred outside of this period, and there was an of discharges happened.

important peak between 13:00 and 16:59, wherein 40.94\%

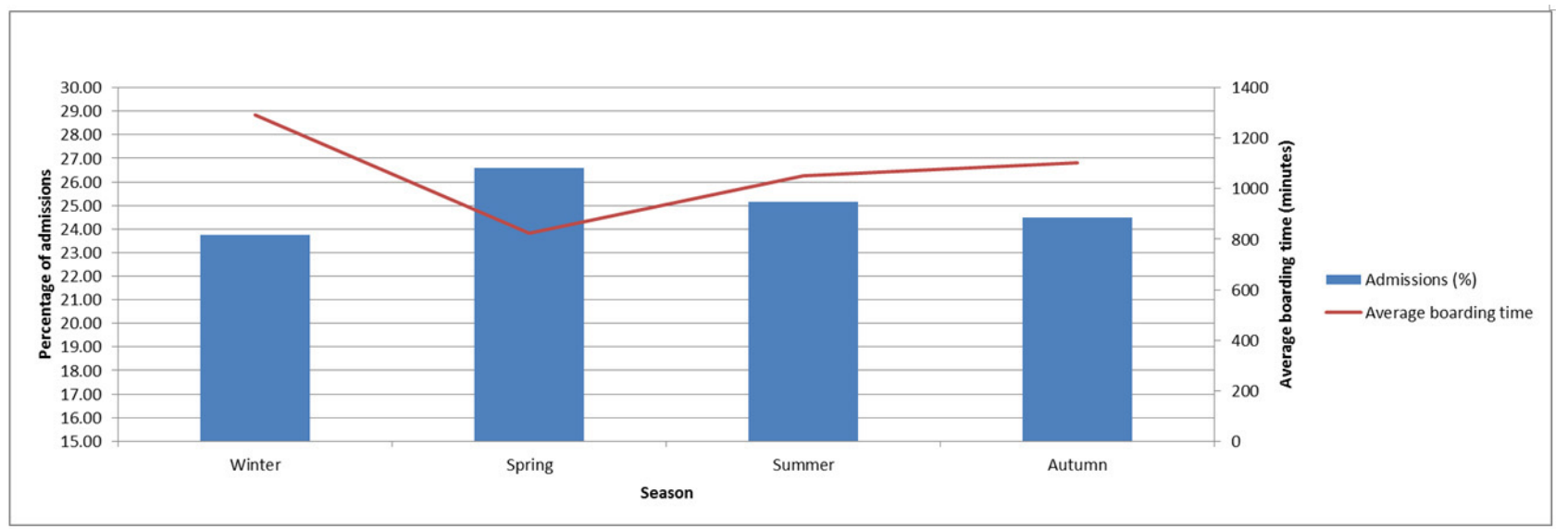

Figure 2. Hospital A - Admission requests and average boarding time by season

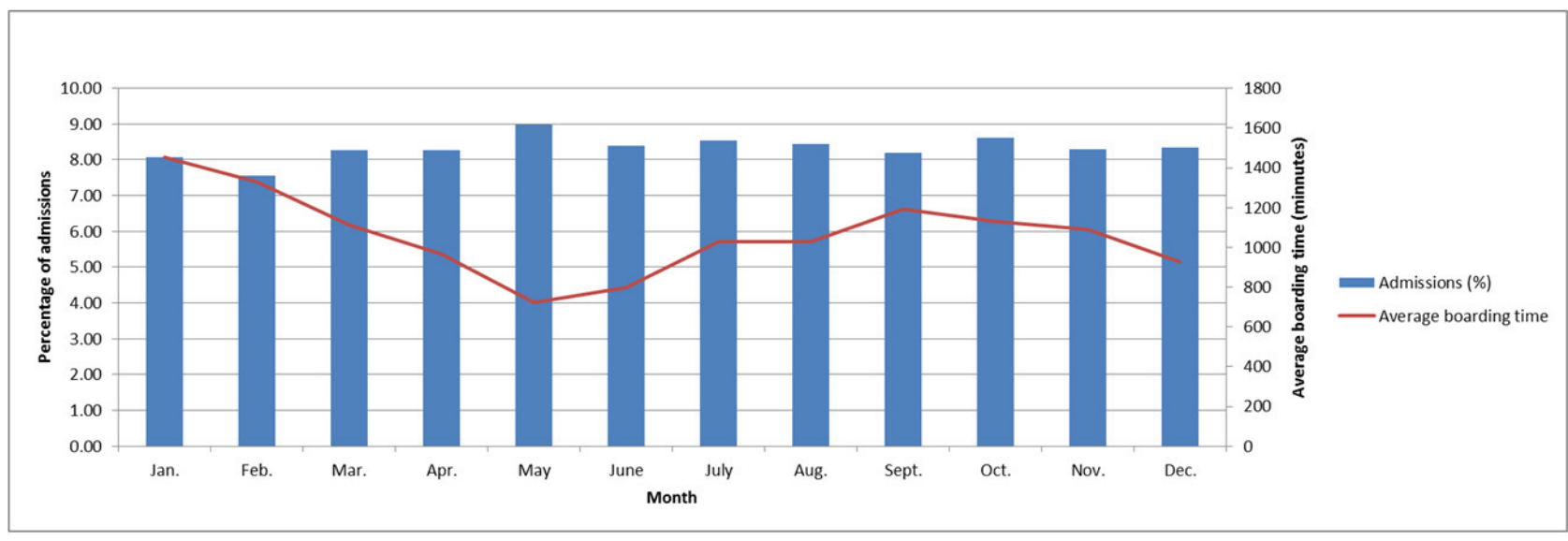

Figure 3. Hospital A - Admission requests and average boarding time by month

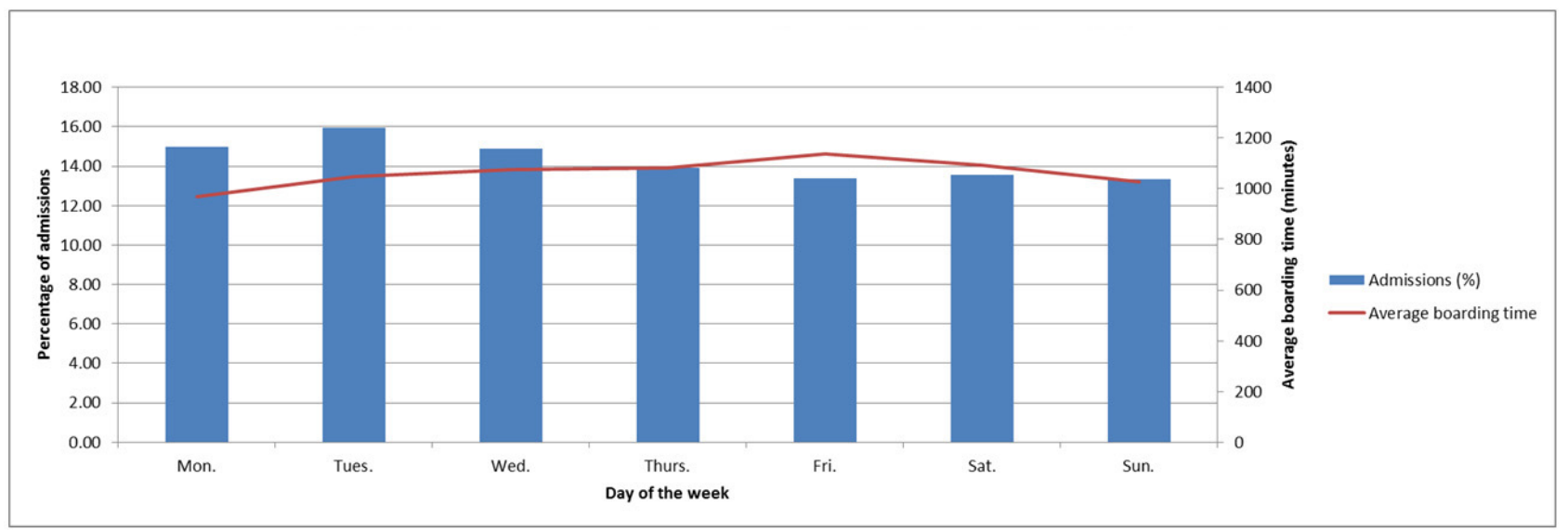

Figure 4. Hospital A - Admission requests and average boarding time by day of the week 


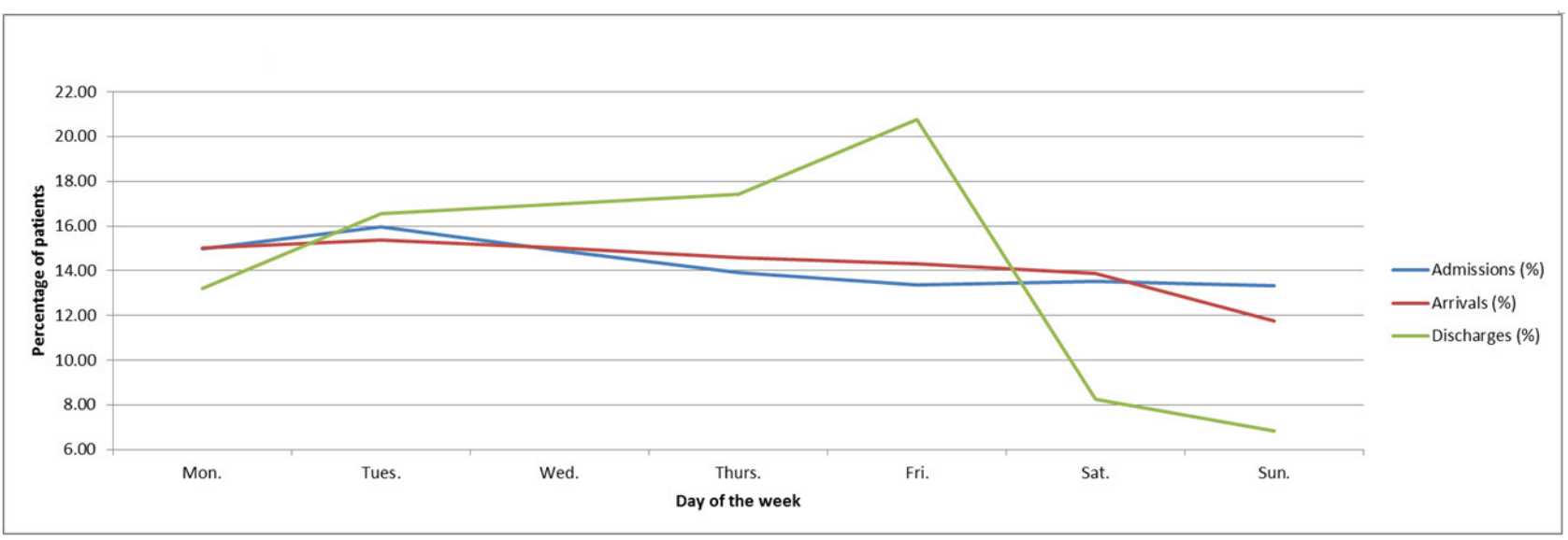

Figure 5. Hospital A - Admission requests (\%), arrivals (\%) and discharges by day of the week

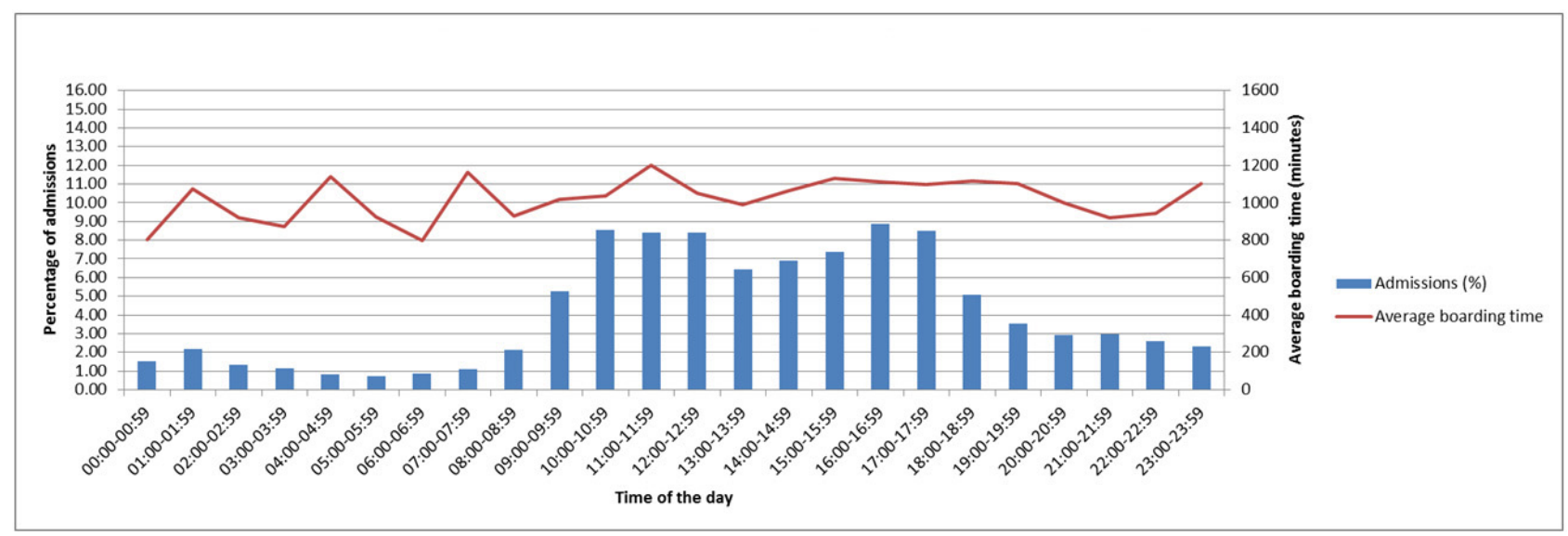

Figure 6. Hospital A - Admission requests and average boarding time by time of day

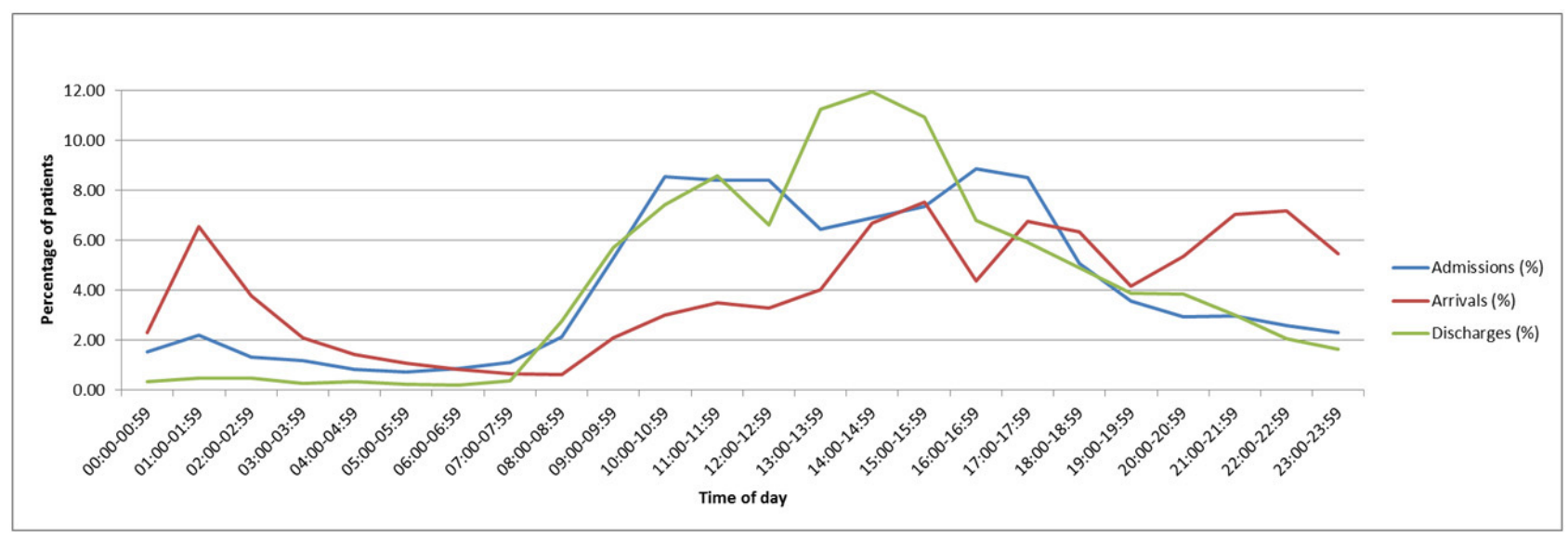

Figure 7. Hospital A - Admission requests (\%), arrivals (\%) and discharges by time of day

\subsubsection{Hospital B}

Spring was the season within which most admissions were requested (25.82\%), while Summer saw the least admission requests $(23.10 \%)$. The season with the poorest performance in terms of average boarding time was Summer $(1,005.35$

Published by Sciedu Press minutes), while Autumn had the lowest average boarding time of all seasons (478.19 minutes) (see Figure 8). Seasons were found to be statistically significant in affecting boarding times $(p \leq .0001)$.

December was the month within which most admissions 
were requested $(9.62 \%)$, while June saw the least admission requests $(6.84 \%)$. The month with the poorest performance in terms of average boarding time was June (1,383.13 minutes), while November had the lowest average boarding time of all months (245.61 minutes) (see Figure 9). Months were found to be statistically significant in affecting boarding times $(p \leq .0001)$.

Tuesday was the day of the week within which most admissions were requested (15.67\%), while Sunday saw the least admission requests $(11.55 \%)$. The day of the week with the poorest performance in terms of average boarding time was Monday (937.13 minutes), while while Friday had the lowest average boarding time of all days of the week (460.82 minutes) (see Figure 10). Finally, Friday saw the most discharges $(22.65 \%)$, while Sunday had the least (6.63\%) (see Figure 11). Days of the week were found to be statistically significant in affecting boarding times $(p \leq .0001)$.

16:00-16:59 was the hour within which most admissions were requested (15.44\%), while 05:00-05:59 saw the least admission requests $(0.07 \%)$. The hour with the poorest per- formance in terms of average boarding time was 23:00-23:59 (1,021.11 minutes), while 06:00-06:59 had the lowest average boarding time of all hours (360.06 minutes) (see Figure 12). Finally, 14:00-14:59 had the most discharges (14.81\%), while 03:00-03:59 had the least $(0.16 \%)$ (see Figure 13). Hours were found to be statistically significant in affecting boarding times $(p \leq .0001)$.

$45.56 \%$ of admissions were requested between 08:00 and 15:59, the period within which the hospital has the most personnel. $54.44 \%$ of admissions were requested outside of this period. There was an important peak between 15:00 and 18:59, wherein 51.54\% of admissions were requested. $27.67 \%$ of arrivals occurred between 08:00 and 15:59. $68.33 \%$ of patients arrived to their IP beds outside of this period, and there was an important peak between 18:00 and $21: 59$, wherein $35.10 \%$ of arrivals occurred. $67.56 \%$ of discharges happened between 08:00 and 15:59. 32.44\% of discharges occurred outside of this period, and there was an important peak between 13:00 and 16:59, wherein 49.47\% of discharges happened.

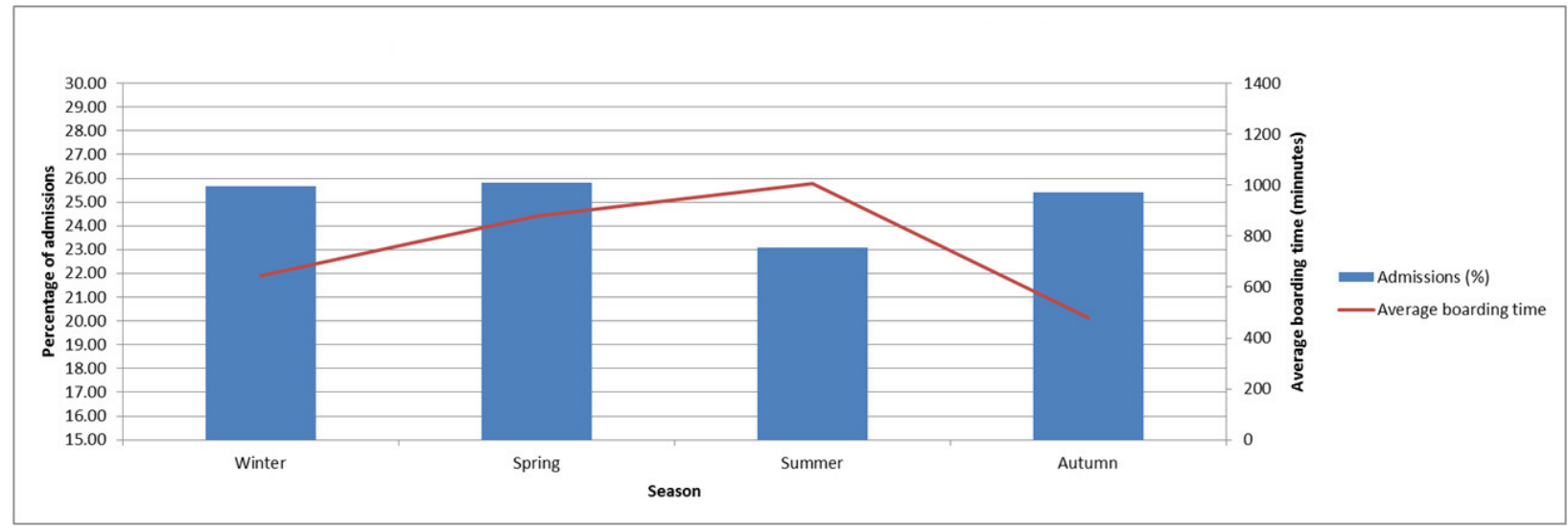

Figure 8. Hospital B - Admission requests and average boarding time by season

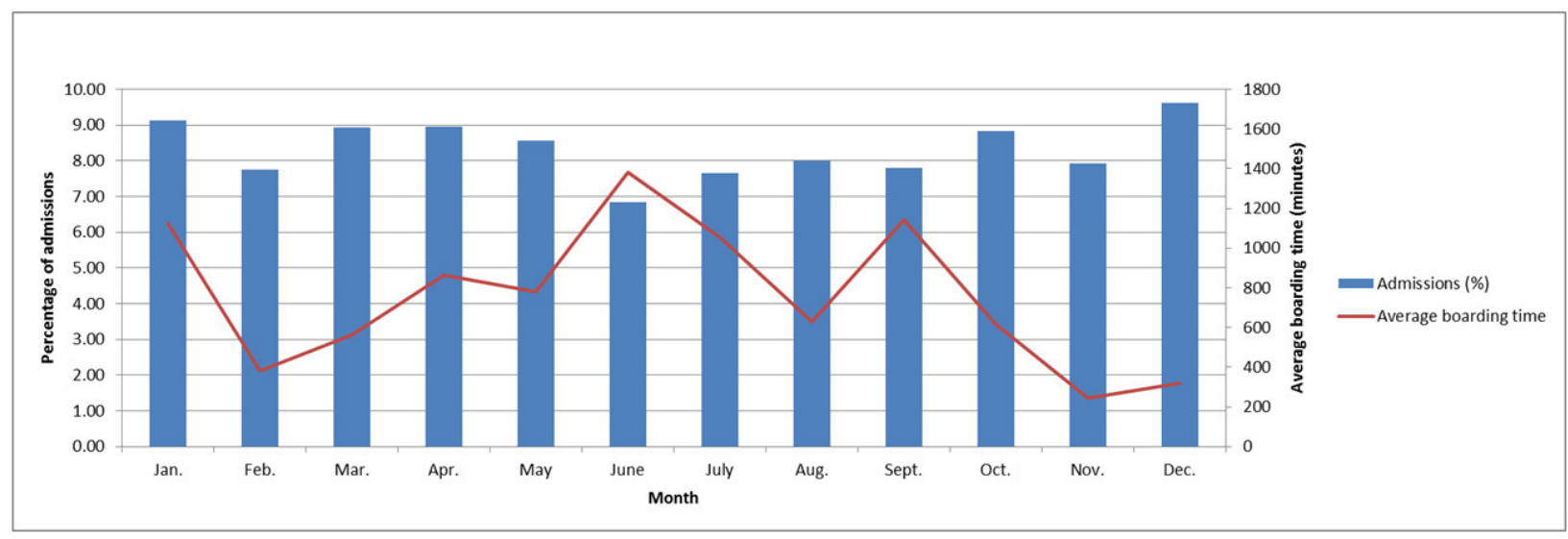

Figure 9. Hospital B - Admission requests and average boarding time by month 


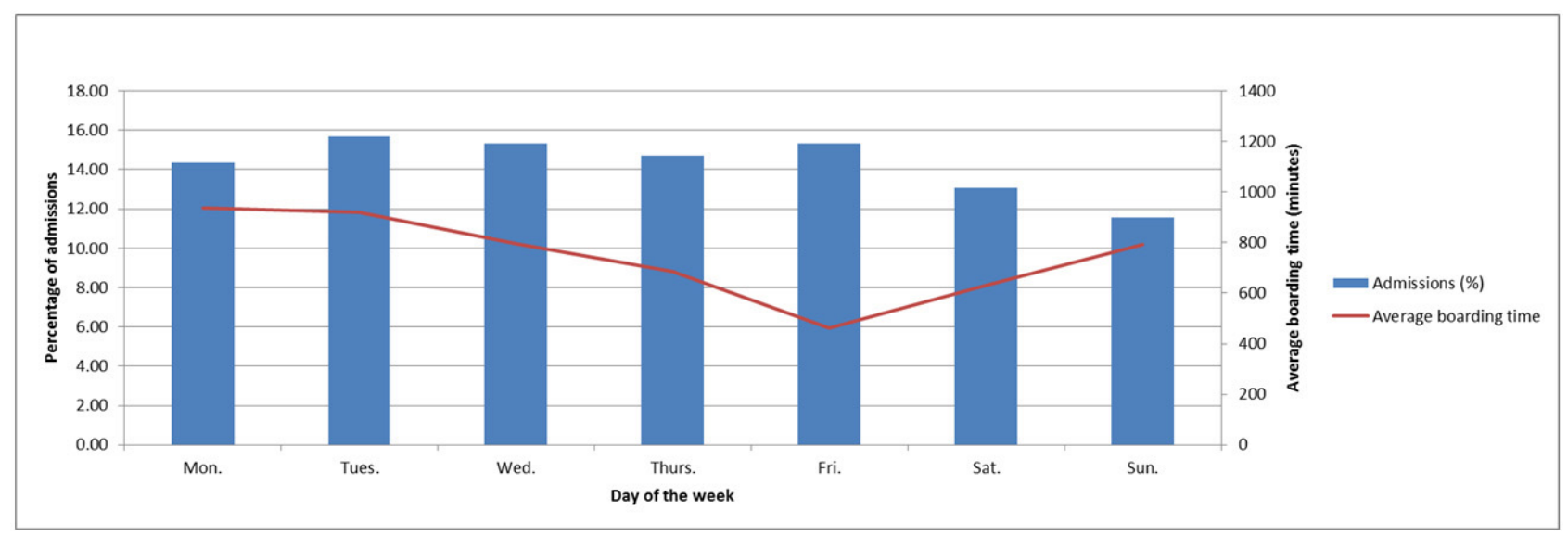

Figure 10. Hospital B - Admission requests and average boarding time by day of the week

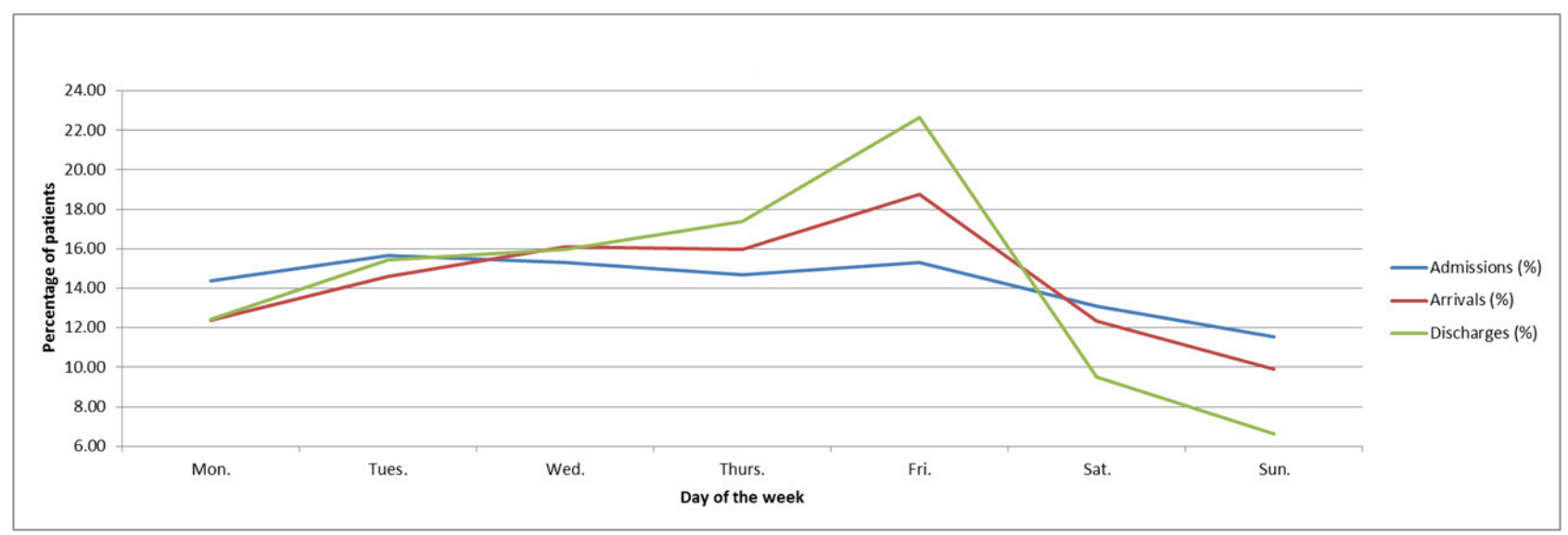

Figure 11. Hospital B - Admission requests (\%), arrivals (\%) and discharges by day of the week

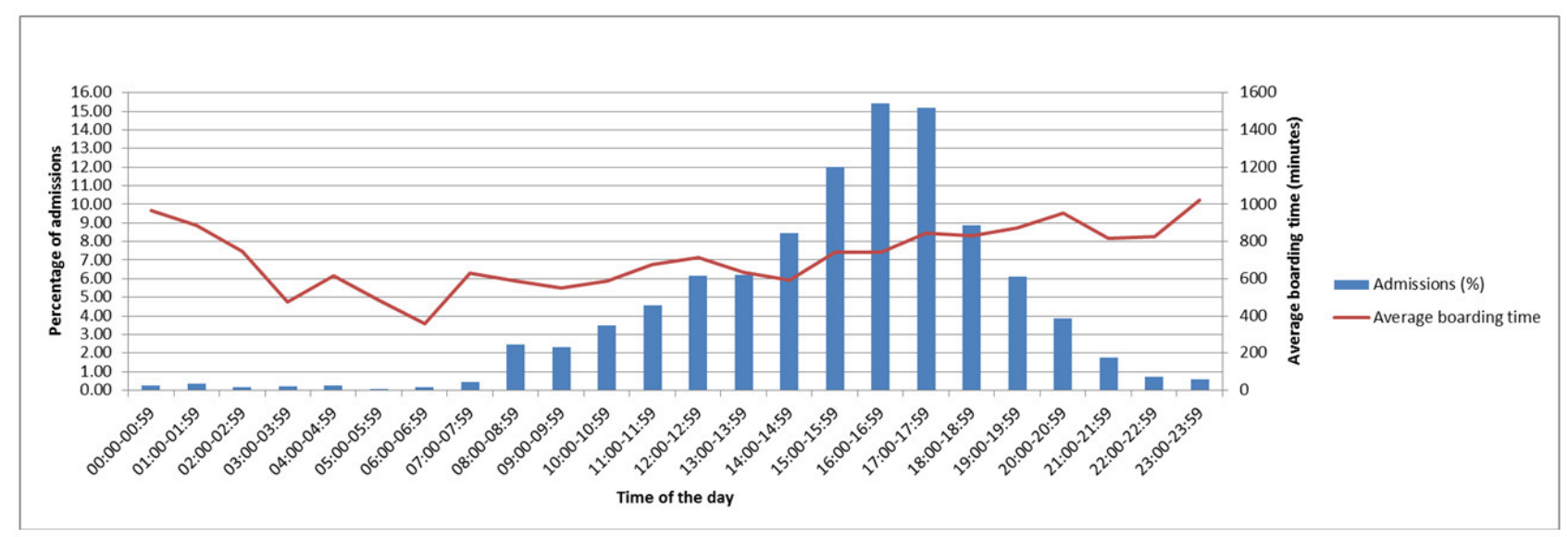

Figure 12. Hospital B - Admission requests and average boarding time by time of day

\subsubsection{Hospital C}

Spring was the season within which most admissions were requested $(25.81 \%)$, while Winter saw the least admission requests $(24.29 \%)$. The season with the poorest performance in terms of average boarding time was Spring $(1,165.97 \mathrm{~min}-$

Published by Sciedu Press utes), while Summer had the lowest average boarding time of all seasons (737.58 minutes) (see Figure 14). Seasons were found to be statistically significant in affecting boarding times $(p \leq .0001)$. 


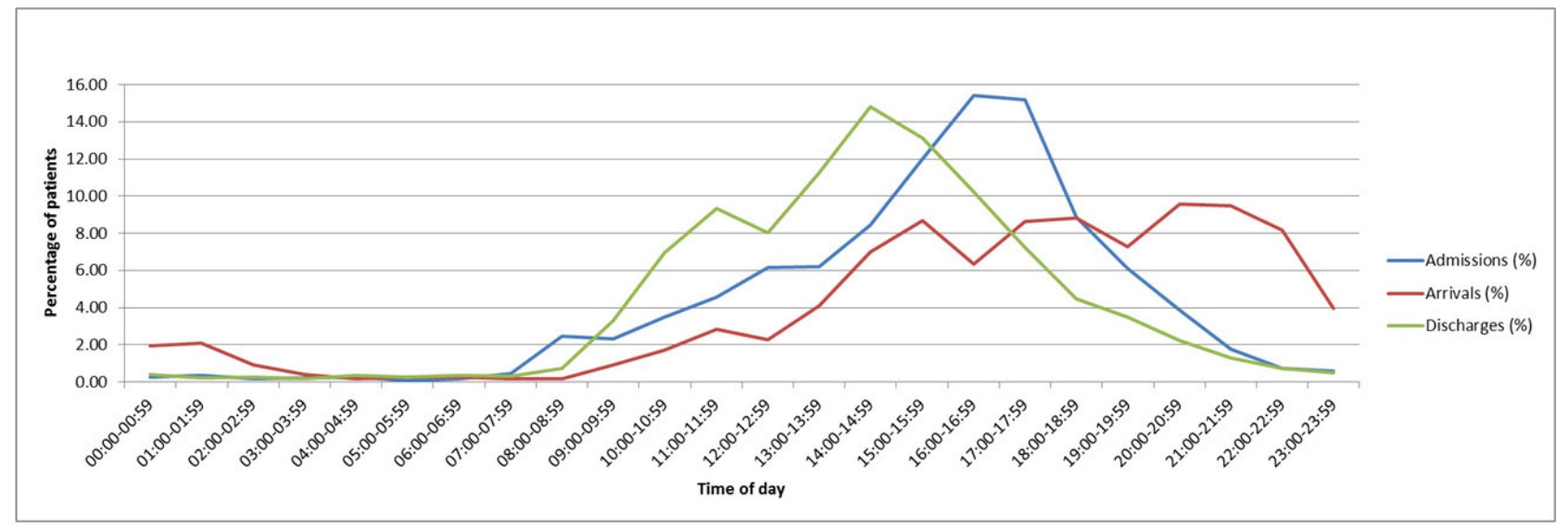

Figure 13. Hospital B - Admission requests (\%), arrivals (\%) and discharges by time of day

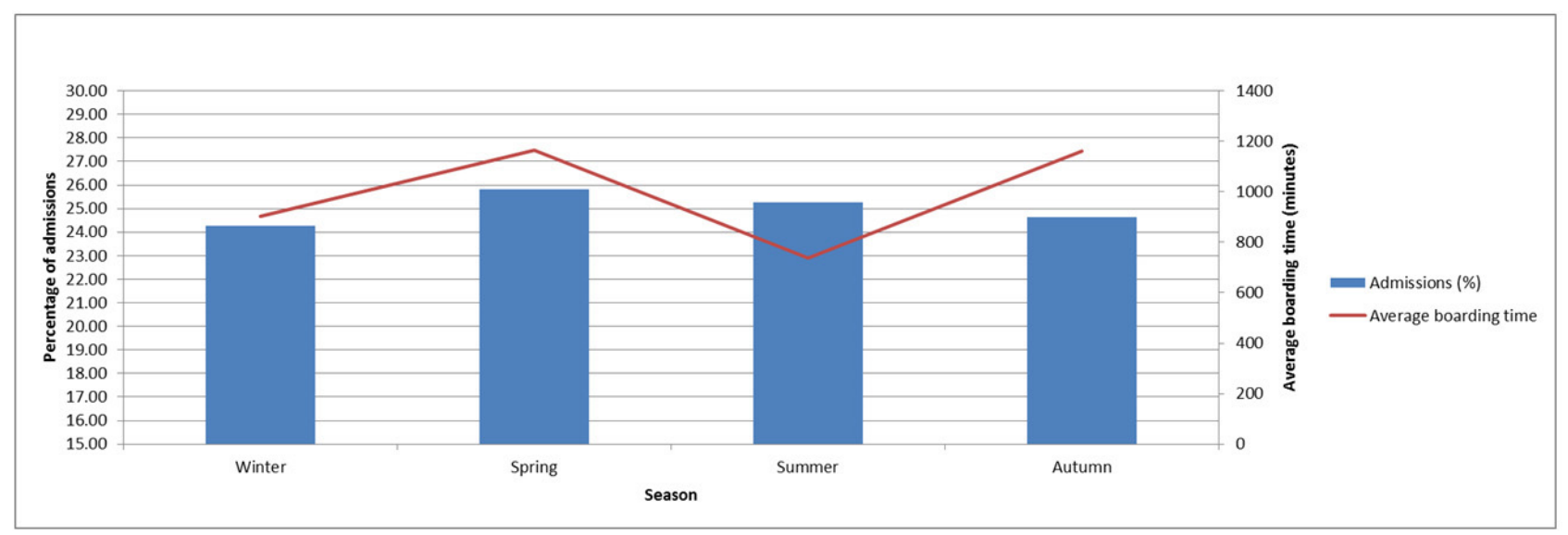

Figure 14. Hospital C - Admission requests and average boarding time by season

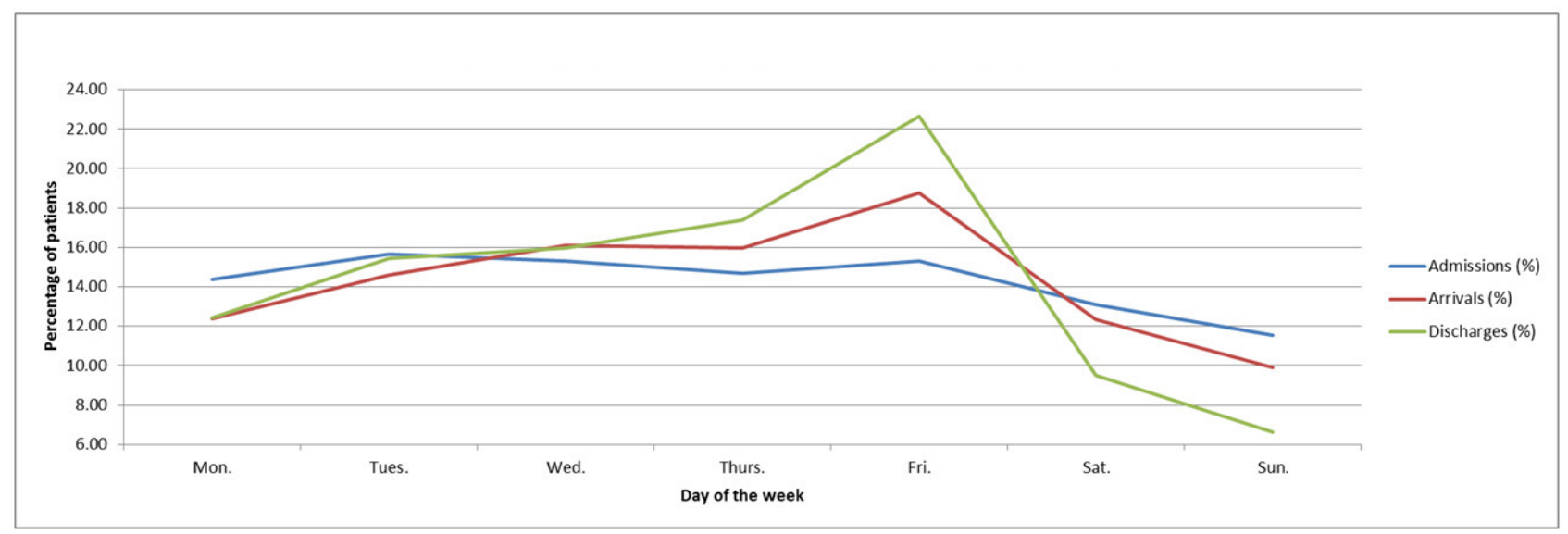

Figure 15. Hospital C - Admission requests and average boarding time by month

January was the month within which most admissions were requested $(8.76 \%)$, while February saw the least admission requests $(7.80 \%)$. The month with the poorest performance in terms of average boarding time was April (1,569.35 min- utes), while July had the lowest average boarding time of all months (638.57 minutes) (see Figure 15). Months were found to be statistically significant in affecting boarding times $(p \leq .0001)$. 
Friday was the day of the week within which most admissions were requested (15.63\%), while Sunday saw the least admission requests (12.38\%). The day of the week with the poorest performance in terms of average boarding time was Sunday (1,194.37 minutes), while Friday had the lowest average boarding time of all days of the week (769.27 minutes) (see Figure 16). Finally, Friday saw the most discharges (19.15\%), while Sunday had the least (10.00\%) (see Figure 17). Days of the week were found to be statistically significant in affecting boarding times $(p \leq .0001)$.

14:00-14:59 was the hour within which most admissions were requested $(8.71 \%)$, while 04:00-04:59 saw the least admission requests $(0.80 \%)$. The hour with the poorest performance in terms of average boarding time was 03:00-03:59 (1,488.93 minutes), while 13:00-13:59 had the lowest average boarding time of all hours ( 813.30 minutes) (see Figure 18). Finally, 14:00-14:59 had the most discharges (12.87\%), while 02:00-02:59 had the least $(0.31 \%)$ (see Figure 19). Hours were found to be statistically significant in affecting boarding times $(p \leq .0001)$.

$41.83 \%$ of admissions were requested between 08:00 and $15: 59$, the period within which the hospital has the most personnel. $58.17 \%$ of admissions were requested outside of this period. There was an important peak between 14:00 and 17:59, wherein $32.10 \%$ of admissions were requested. $23.94 \%$ of arrivals occurred between 08:00 and 15:59. $76.06 \%$ of patients arrived to their IP beds outside of this period, and there was an important peak between 19:00 and $22: 59$, wherein $36.39 \%$ of arrivals occurred. $59.49 \%$ of discharges happened between 08:00 and 15:59. 40.51\% of discharges occurred outside of this period, and there was an important peak between 13:00 and 16:59, wherein 40.84\% of discharges happened.

\subsection{Qualitative results}

How the different categories of respondents (administration and clinical/support staff) have contributed to the resulting framework is shown in Table 1 (Causes) and Table 2 (Solutions).

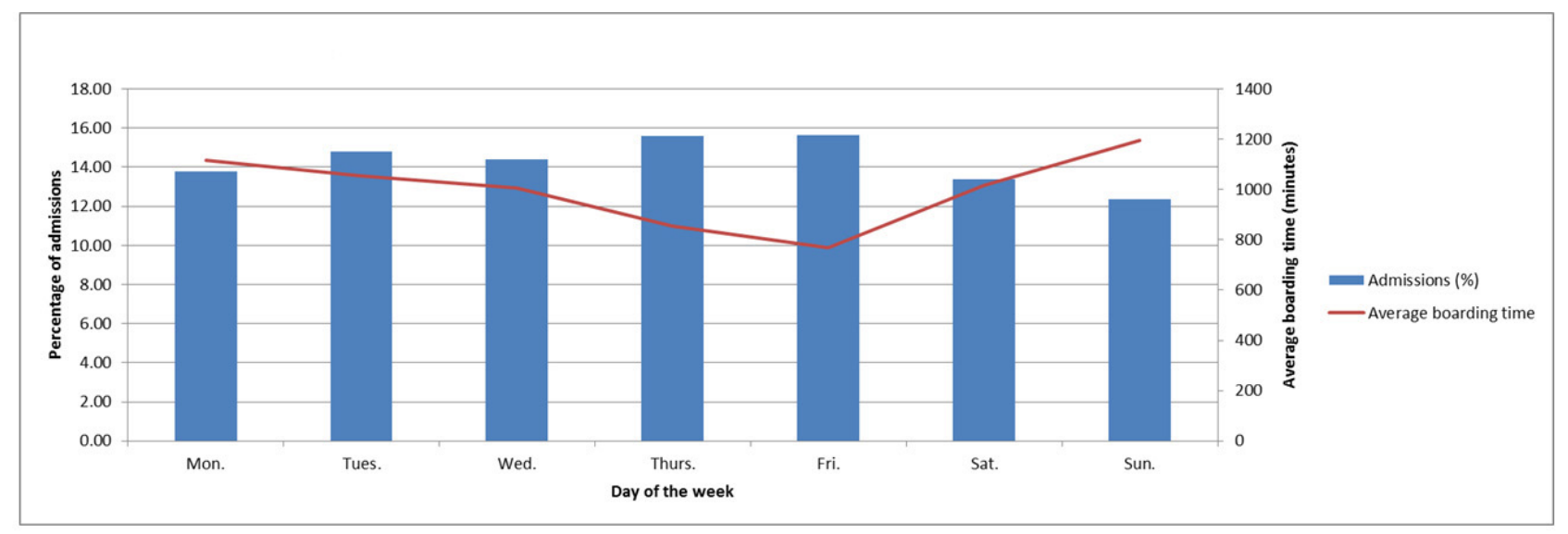

Figure 16. Hospital $\mathrm{C}$ - Admission requests and average boarding time by day of the week

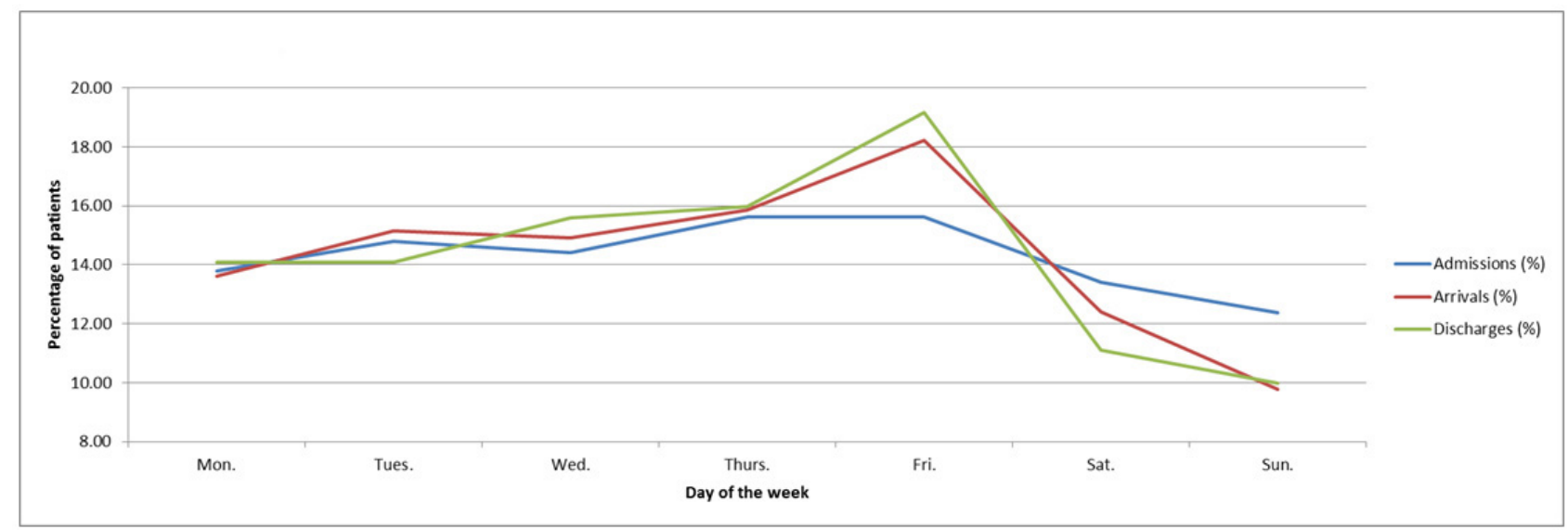

Figure 17. Hospital C - Admission requests (\%), arrivals (\%) and discharges by day of the week 


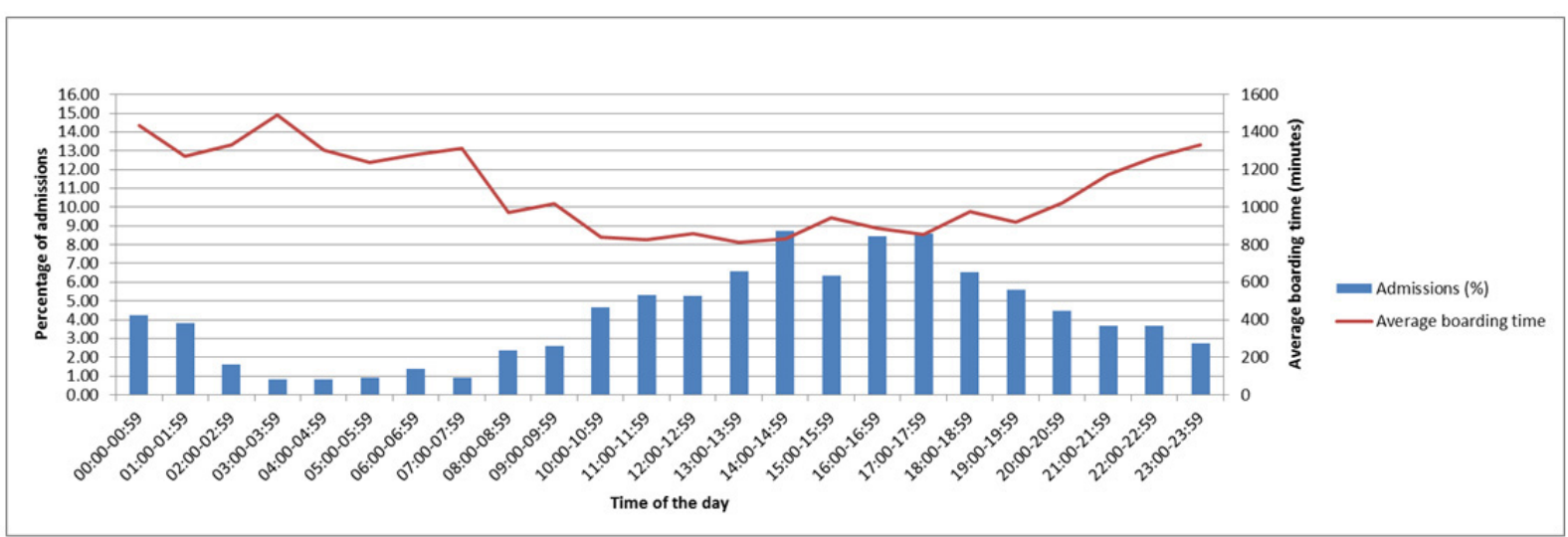

Figure 18. Hospital $\mathrm{C}$ - Admission requests and average boarding time by time of day

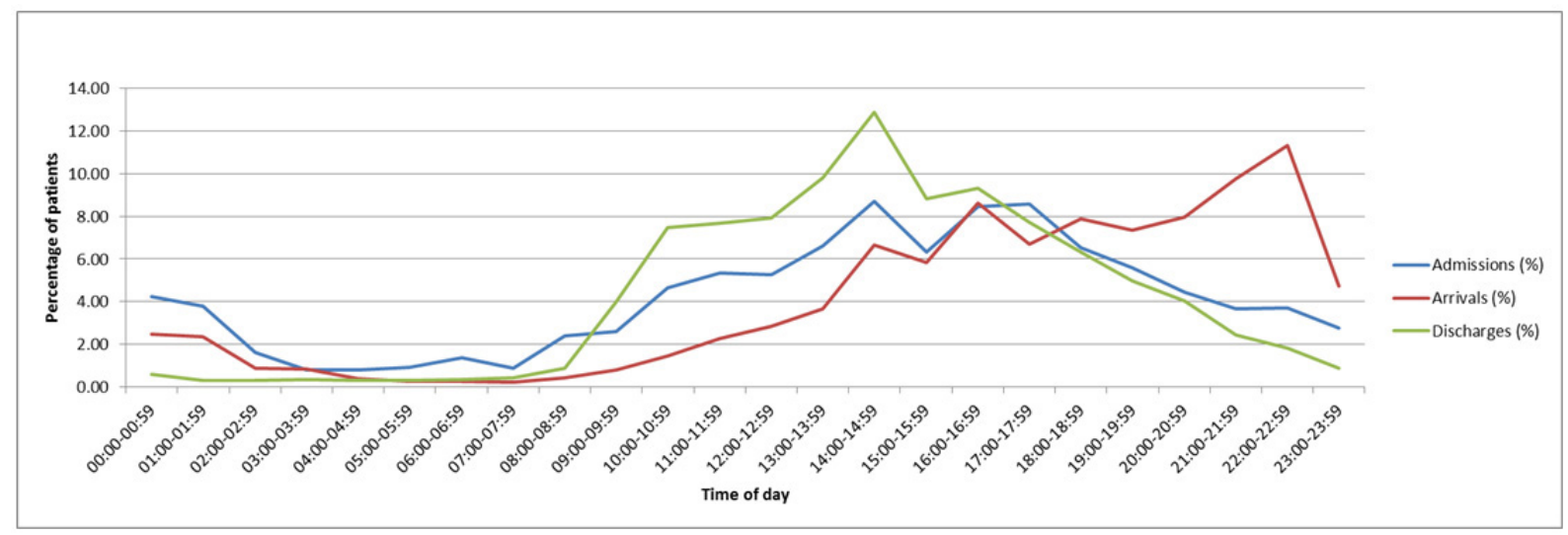

Figure 19. Hospital $\mathrm{C}$ - Admission requests (\%), arrivals (\%) and discharges by time of day

\section{Discussion}

Using Figure 20 as a framework for illustrating the causes and solutions of ED boarding, this section is separated into four subsections addressing causes and solutions of each category: input, throughput, output causes, and the global category which was added to the initial framework posited by Asplin et al. ${ }^{[6]}$ after having completed the field work.

\subsection{Causes and solutions: Input category}

Input factors related to the ED include "any condition, event, or system characteristic that contributes to the demand of ED services". ${ }^{[6]}$ This means that fluctuations in demand due to such things as population growth, non-urgent patient flux, or frequent users are considered to be input factors.

Andersson and Karlberg wrote about the importance of fluctuations in demand for healthcare services. ${ }^{[14]}$ McCarthy et al. distinguished significant variations according to seasons and years. ${ }^{[15]}$ The literature on this topic is extensive and it is to be expected that there are many surges in a given year that can affect the levels of ED boarding. While none of the interviewed participants pinpointed fluctuations in demand as a key issue in ED boarding, the quantitative data demon- strates that it has a significant effect on the levels of boarding time. In the SAS general linear model, the effect of seasons and months on ED boarding time was found to be statistically significant for every hospital $(p<.0001)$. Additionally, the combined general linear model which compared each hospital to one another also found both of these variables to be statistically significant $(p \leq .0001)$. Although both the literature and the quantitative data support this as a key issue in ED boarding; we do not present any particular solutions to this problem, as the issues causing the variations can be multifactorial, whether related to public health, health policies, or other such factors that are outside of the boundaries of this research. One important conclusion is that hospital administration and clinical/support staff should take into account demand fluctuations more explicitly to better understand ED boarding time.

\subsection{Causes and solutions: Throughput category}

Throughput factors are made up of all the different aspects of ED care from patient arrival to patient discharge, transfer, or death. This includes processes such as triage, room placement, physician evaluation, and treatment. The admission process in itself is also part of throughput factors. 
Table 1. Qualitative interview results (Causes)

\begin{tabular}{|c|c|c|c|c|c|c|c|c|}
\hline & \multirow{2}{*}{ Causes } & \multicolumn{3}{|c|}{ Administration } & \multicolumn{3}{|c|}{ Clinical/Support staff } & \multirow{2}{*}{ Total (\#) } \\
\hline & & Hosp A & Hosp B & Hosp C & Hosp A & Hosp B & Hosp C & \\
\hline \multirow{4}{*}{ Input } & Fluctuations in demand & & & & & & & 0 \\
\hline & Non-urgent patients & & & & & & & 0 \\
\hline & Frequent users & & & & & $1(*)$ & & 1 \\
\hline & Discharged patients returning & & & & & & & 0 \\
\hline \multirow{4}{*}{ Throughput } & Changes in resources & & & & & & & 0 \\
\hline & Ancillary service delays & & 1 & & & 1 & & 2 \\
\hline & Staffing levels & & 1 & & 1 & 2 & 1 & 4 \\
\hline & Physician training & & & & & & & 0 \\
\hline \multirow{4}{*}{ Output } & Hospital restructuring & & & & & & & 0 \\
\hline & Hospital bed shortages & 1 & & & & & 1 & 2 \\
\hline & Late discharges & 2 & 3 & 3 & 3 & 2 & 2 & 15 \\
\hline & Uncoordinated admissions/discharges & 2 & 4 & 2 & & 1 & 2 & 11 \\
\hline \multirow{5}{*}{ Field causes } & Resources related to specific patient needs & 1 & 1 & 3 & 4 & 1 & 3 & 13 \\
\hline & Specific patient disposition (e.g. VRE+) & 2 & & 3 & 4 & 2 & 2 & 13 \\
\hline & Inability to discharge patients & 5 & 2 & 2 & 2 & 3 & 2 & 16 \\
\hline & Lack of communication/information & 4 & 4 & 2 & 1 & 3 & 3 & 17 \\
\hline & Imbalance in surgical scheduling & 3 & & 1 & 1 & & & 5 \\
\hline
\end{tabular}

Note. Causes $(*)$ indicates the number of interviewees mentioning the cause

Table 2. Qualitative interview results (Solutions)

\begin{tabular}{|c|c|c|c|c|c|c|c|c|}
\hline & \multirow{2}{*}{ Solutions } & \multicolumn{3}{|c|}{ Administration } & \multicolumn{3}{|c|}{ Clinical/Support staff } & \multirow{2}{*}{ Total (\#) } \\
\hline & & Hosp A & Hosp B & Hosp C & Hosp A & Hosp B & Hosp C & \\
\hline \multirow{4}{*}{ Literature } & Coordinating discharges/admissions & $5(*)$ & 4 & 4 & 3 & 2 & 3 & 21 \\
\hline & Improving admission process & 1 & 2 & 3 & 1 & 1 & 3 & 11 \\
\hline & Improving inpatient bed management & 3 & & 1 & 1 & & 1 & 6 \\
\hline & Smoothing elective surgery schedules & 5 & & 1 & 1 & & & 7 \\
\hline \multirow{5}{*}{$\begin{array}{l}\text { Field } \\
\text { solutions }\end{array}$} & Improving communication/collaboration & 5 & 4 & 3 & 4 & 4 & 4 & 24 \\
\hline & Improving resource management & & 1 & 1 & & 2 & 3 & 7 \\
\hline & Improving inf. disease management & & 3 & 2 & 1 & 1 & 2 & 9 \\
\hline & Preparing discharge more extensively & 5 & 4 & 2 & 4 & 2 & 3 & 20 \\
\hline & Improving external resources & 1 & 1 & 2 & & 1 & 1 & 6 \\
\hline
\end{tabular}

Note. Solutions $(*)$ indicates the number of interviewees mentioning the solution

\subsubsection{Ancillary service delays}

Ancillary service delays were mentioned as a key issue in causing ED boarding by 2 interviewees. Ancillary services are traditionally defined as "procedures required prior to visiting a physician", ${ }^{[16]}$ such as $x$-rays or laboratory analyzes; however, other tests that are requested by a physician, sometimes after admission is requested but before the patient is transferred, are qualified as such as well. Davis et al. ${ }^{[17]}$ found that ancillary services can experience considerable delays, increasing patient length of stay (LOS) in the ED, and this was found to be a common occurrence in the studied hospitals. There are two main types of ancillary service delays experienced by boarded patients. The first is related to infectious disease prevention, whereby patients are screened for various infectious diseases (VRE, methicillin-resistant staphylococcus aureus [MRSA], Clostridium, etc.); patients arriving to the ED from long-term care facilities, or from other hospitals, are obligatorily screened for these infections, and can thus experience considerable delays after their admission is requested before arriving to an IP unit. The second Published by Sciedu Press is related to physician requests; on some occasions, consulting physicians will request a patient to be admitted, but also request additional tests be conducted prior to his arrival to the IP unit. This most often occurs when patients are unstable.

No solutions were posited by the interviewees in this regard, however, the literature offers many alternatives, such as the use of continuous improvement practices ${ }^{[18]}$ and optimization modeling to find which aspects of ancillary services are causing delays. ${ }^{[19]}$

\subsubsection{Staffing levels}

Staffing levels in the ED and the IP units were mentioned as a key issue in causing ED boarding by 5 interviewees. Many authors have addressed staffing levels, ${ }^{[20]}$ generally regarding nursing levels and the number of physicians available per patient. Additionally, the literature review showed a link between staffing levels and ED crowding. ${ }^{[1]}$ As per the literature, proper staffing levels are required in order to promote patient flow and ensure that proper care is given. 


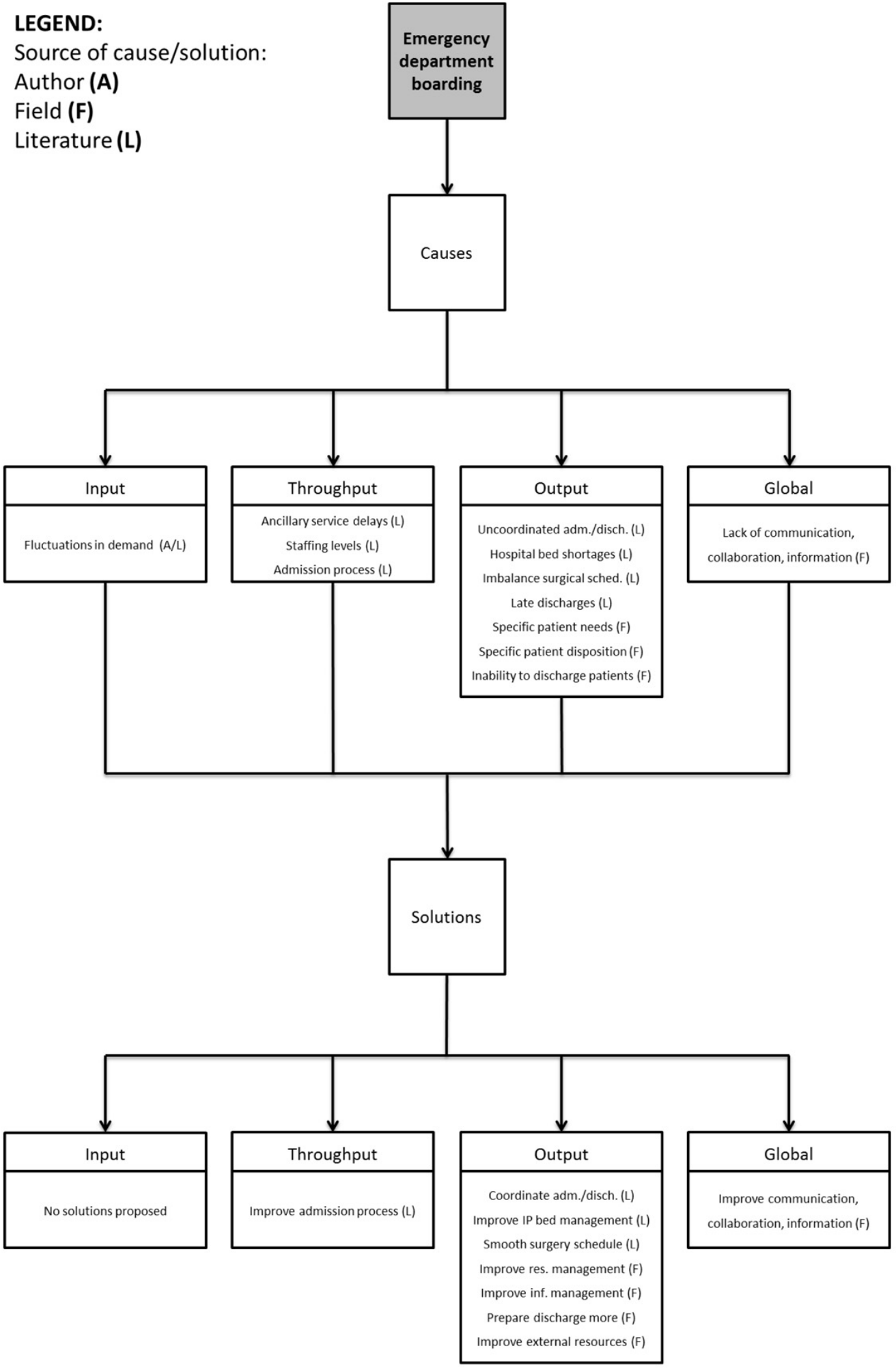

Figure 20. Integrative conceptual framework displaying the causes and solutions of ED boarding validated in the field work

The main concern of the interviewed participants in these regards was that batching of admissions, transfers (arrivals) or discharges was too frequent, and that during these periods, the staff available had difficulties coping with the amount of work that ensued. Admissions and discharges are not coordinated and most patients are discharged too late in the day; in both cases, everything is done in batches, and there are important peak days and times, which greatly influence 
the workload for the staff available during those times. No solutions were proposed by any of the interview participants.

\subsubsection{Admission process}

Improving the admission process was mentioned as a key solution to ED boarding by 11 interviewees. While it was not mentioned as a key cause to ED boarding, it received an important number of comments in regards to possible solutions to this issue. One of the main concerns voiced by the interviewees was that in order for a patient to be transferred to an IP unit, the AHN from the ED has to speak directly to the AHN from the IP unit. They cannot transfer a patient until the two have dialogued as to the readiness of the IP unit to receive the patient. Evidently, this can cause problems and delay the patient's transfer. Many of the interviewees said that during periods where AHNs were on a break, this process could not be completed, and that many times AHNs participated in patient care activities, and as such were not present at the desk to receive the calls for confirmation.

Avoiding redundancies and creating a leaner and more efficient admission process was also suggested in the literature. Standardizing the admission process to a greater extent could for example benefit hospitals, as can be seen in Ortiga et al. ${ }^{[22]}$ Ensuring that the process is as easy and comprehensive as possible could benefit the studied hospitals and help them reduce the number of boarders and their average boarding time.

\subsection{Causes and solutions: Output category}

Output factors are comprised of all the different factors that prevent patients from being discharged or transferred from the ED, or that affect hospital and system characteristics.

\subsubsection{Uncoordinated admissions/discharges}

The lack of coordination between admissions and discharges was mentioned as a key cause of ED boarding by 11 interviewees. Liu et al. found that coordinating admissions and discharges was the most beneficial approach for limiting levels of ED boarding, and the number of interview participants who shared this point of view was considerable. ${ }^{[23]}$ Coordinating admissions and discharges was mentioned as a potential solution to ED boarding by 21 out of the 25 interview participants.

This prominence of this issue is validated by the quantitative evidence when comparing the three hospitals. The hospitals that most often mentioned the lack of coordination between admissions and discharges as a key issue are also those which were found to be significantly affected by days of the week in the SAS model. In other words better coordination between admissions and discharges reduces the impact of peaks in demand during the week.

Published by Sciedu Press

\subsubsection{Hospital bed shortages}

In the current context, "bed shortages" is related to physical resources. As per the literature review, we know that adding more beds generally does not solve issues related to patient throughput within the patient care process. Several authors ${ }^{[24,25]}$ attempted to find a beneficial link between adding more hospital beds and ED boarding, but in each case their studies proved that adding more beds did not improve the issue. Adding beds in a specific unit may lower boarding times for patients of that particular type, ${ }^{[24]}$ but inevitably require additional resources to maintain, and do not present benefits for other patient types. Moreover, capacity cannot so easily be increased; more beds will often lead to using them in an inefficient way. The goal is to use the resources available in a more optimal way, and it is by altering how resources are used that this goal will be achieved. This issue did not come up in any additional documentation and could not be corroborated with quantitative data. Given that very few participants mentioned hospital bed shortages as an issue in causing ED boarding, and given that the literature demonstrates that management is more important than the amount of physical resources available for hospital beds, hospital bed shortages are not considered to be a key issue in causing ED boarding in this study.

\subsubsection{Imbalance in surgical scheduling}

Imbalances in surgical scheduling was mentioned as a key issue in causing ED boarding by 5 interviewees. The participants who mentioned this as a key issue all interact with surgical schedules directly. Rathlev et al. found that imbalanced surgical schedules had a link with decreases in throughput, and this was corroborated with the qualitative data. ${ }^{[26]}$ With the number of surgeries requiring hospitalization growing in the participating hospitals, imbalanced surgery schedules become more and more of a factor in causing ED boarding.

Imbalanced surgery schedules can affect ED boarding in two ways. First, when the number of surgeries requiring hospitalization is very high on a given day, many beds are reserved for these patients, and as such, cannot be used for admitted ED patients. Moreover, these beds are often empty for long periods of time while patients are in surgery; given the limited amount of resources available, this is not an optimal allocation of these resources. Second, when surgeons are in the operating room (OR) for an entire day, this is a lengthy period of time within which they are not discharging patients that were attributed to them, which means that beds that could otherwise have been attributed to ED patients are not available.

The solution to this problem is to smooth the surgery schedule so as to decrease the large fluctuations in bed reservations 
that can be experienced currently. Although the solution is evident, the approach can be complex, as there are many different factors that play into scheduling. ${ }^{[27]}$ Taking into account that certain factors such as day of the week or month have an impact on the emergency boarding time, it is advisable to use the insights from the quantitative model when trying to smooth the surgery schedule.

\subsubsection{Late discharges}

Late discharges were mentioned as a key issue in causing ED boarding by 15 interview participants. In the current context, late discharges refer to discharges that are done late in the day, and not discharges that are delayed because of external or patient-related factors.

The prominence of late discharges was validated through the quantitative evidence. All three hospitals experience the same peak discharge time, which is 14:00-14:59, and all three hospitals experience the same peak 4-hour period, which is from 13:00 to 16:59. In the interviews, participants said that this hindered patient flow, as patients are generally transferred from the ED to an IP care unit 2 hours after a bed has been vacated, the period within which the bed and room are cleaned and sanitized, and the patient is prepped to leave the ED. What we see, then, is an equally important spike in patient arrivals that happens late in the day, when there are fewer staff members (after 15:59) and resources available.

Both the qualitative and the quantitative data show that this is an important issue in causing ED boarding, and this is further corroborated by the literature. ${ }^{[28]}$ Quite often, patients are discharged but cannot leave immediately for one reason or another, which is yet another reason to discharge patients earlier, in order to ensure that they can leave as soon as possible.

The main solution, then, is to shift the peak earlier in the day, as Powell et al. did in a simulation study. ${ }^{[28]}$ Improving IP bed management was posited as a potential solution to ED boarding by 6 interview participants. There are many authors who wrote about "discharge by noon" initiatives, which address this issue as well. ${ }^{[29]}$ Complementary, it could be beneficial to standardize the discharge process more extensively. None of the visited hospitals have "waiting rooms" or "lounge" for discharged patients, although some of them experimented with this concept, but found that it was not beneficial. Through the literature review, we've found that having more physical resources often does not solve the problems experienced by hospitals, and this is another example of such an issue.

\subsubsection{Resources related to specific patient needs}

Specific patient needs (e.g. telemetry, harness for obese patients, etc.) were mentioned as a key issue by 13 inter102 view participants. Interviewees mentioned that one of the main reasons why they struggle in managing this resource is clinical. Patients are monitored on similar equipment in the ED, often for numerous hours and even days, but this period of monitoring is not included when a physician asks for a patient to be monitored for a certain number of hours. For example, a patient is monitored in the ED for 48 hours with no cardiac arrhythmia, and the consulting cardiologist requests his admission with 72 hours of telemetry monitoring. As the initial 48 hours will not be counted within the physician's request, an additional 72 hours of monitoring will be conducted.

As with any scarce resource, improving resource management is an important solution to this problem. The allocation of scarce resources in healthcare has received considerable interest in the academic world. Optimizing resource use or reducing the demand for particular resources ${ }^{[30]}$ and choosing which patients receive particular resources according to guidelines ${ }^{[31]}$ or according to the patient's degree of need ${ }^{[32]}$ are all solutions proposed to this issue.

\subsubsection{Specific patient disposition}

Specific patient disposition is related to hospital-acquired infections, also known as nosocomial infections, or other such infectious diseases (e.g. tuberculosis). This issue was mentioned as a key cause by 13 interview participants.

The main way to improve this problem is to increase cooperation between bed management employees and infectious disease prevention employees. When patients require isolation, often times beds are lost, as semi-private rooms are used for single patients. This has a considerable impact on bed management practices, and on average boarding times.

\subsubsection{Inability to discharge patients}

The inability to discharge patients was mentioned by 16 interview participants as a key cause for ED boarding. The inability to discharge patients is segmented into three categories:

(1) Patients are awaiting a place in a long-term care facility, or other external resources, and are using a shortterm occupancy bed in the meanwhile;

(2) A patient's discharge is requested without notice, and the availability of adapted transportation, the patient's family, or other resources prevent him from leaving; and

(3) Patients are medically ready to leave, but have been deconditioned through a lengthy stay in the hospital, and as such require rehabilitation or physiotherapy.

Costa et al. found that in their studied hospitals, ALC (alternate level of care) patients awaiting a place in a LTCF 
(long-term care facility) accounted for $41.5 \%$ of total ALC bed days, even though they only represented $8.8 \%$ of total ALC patients. ${ }^{[33]}$ Increasing partnerships with LTCF as proposed by the interviewees could benefit this segment of the issue related to the inability to discharge patients.

Many patients still require medical attention after being discharged, and as such, continue to occupy an IP bed for lengthy periods of time after their discharge is requested. This problem is also corroborated with the literature. According to Ali Pirani, it is important to improve nurse participation in discharge planning and to involve both patients and clinical staff within this process to ensure fluidity. ${ }^{[34]}$

The final segment is related to patients being deconditioned during their stay in an IP care unit. Having a complete treatment plan that is enacted in a timely fashion in collaboration with the required medical practitioners and healthcare professionals is an improvement that could reduce patients deconditioning and thus decrease the number of delayed discharges related to this issue. ${ }^{[35]}$

\subsection{Causes and solutions: Global category}

Global factors are described as factors that influence multiple parts of the patient flow process, that is to say, input, throughput, and output factors. Within the qualitative interviews, the lack of communication, collaboration, and information was the most commonly mentioned cause of ED boarding in the qualitative interviews, having been pinpointed as one of the 4 major key issues by 17 participants. Even more participants mentioned this as a key solution to ED boarding; in fact, 24 out of 25 interview participants said that the issue of ED boarding could be improved by increasing communication, collaboration, and information within the hospital and between the different actors within the patient care process.

Communication plays a crucial role in the transmission of information and as a means of creating a community within the work environment. However, many different interviewees suggested that there was an important lack of communication between the ED and IP units. As Leonard, Graham and Bonacum wrote, "Effective communication and teamwork is essential for the delivery of high quality, safe patient care. Communication failures are an extremely common cause of inadvertent patient harm." [36]

Finally, a lack of information was felt by most of the participants that were interviewed. Different actors encountered this problem differently, but all had issues with the information that was available to them, and found that this could compromise hospital throughput and patient care. Many academics have addressed the topic of lacking information in healthcare environments. Hesselink et al., for example, surveyed physicians, nurses, and patients, and found that the different parties all perceived information to be insufficient. ${ }^{[37]}$ Helles $\varnothing$ and Sogstad, ${ }^{[38]}$ as well as Kannampallil et al. ${ }^{[39]}$ found that different actors (physicians, nurses, etc.) use different strategies to obtain information, and that it is important to cater to these differences when planning the spread of information.

The causes for ED boarding within the case studies have been found, and these causes can now be validated through additional research in other institutions. The causes that were found are summarized in Table 3.

Table 3. Validated causes of ED boarding in the studied hospitals

\begin{tabular}{llll}
\hline Input & Throughput & Output & Global \\
\hline & & - Uncoordinated admissions and discharges & \\
& - Ancillary service & - Imbalanced surgical schedule & - Lack of communication, \\
& & - Late discharges & collaboration, and \\
- Fluctuations in demand & delays & - Patient needs & information \\
& - Admission process & - Patient disposition & \\
& & - Inability to discharge patients & \\
\hline
\end{tabular}

The causes identified in Table 3 can be further reduced to 4 root causes based on their prominence and validity in the qualitative, quantitative, academic and documentary data. While other causes had been validated through different streams of data as well, these were the 4 major key issues that arose from the interpretation of data. Importantly, these causes were significant in each of the hospitals studied, which leads to the belief that perhaps these causes can be deciphered in other hospitals. The integrating framework in Figure 21

Published by Sciedu Press also links to each root cause the potential solutions as formulated in the interviews or in the literature. The lack of communication, collaboration and information is in our study one of the most frequently mentioned prominent causes and solutions of ED boarding.

\section{Limitations of this research}

There are various limitations to this research. A first category of limitations is related to the nature of the data available. As 
there is a good deal of human intervention within the data obtained, both qualitative and quantitative, there are some limitations to the information acquired. Some of the data obtained from the qualitative interviews was impossible to corroborate with the quantitative data within the context of the work, because the required quantitative data was unavailable.

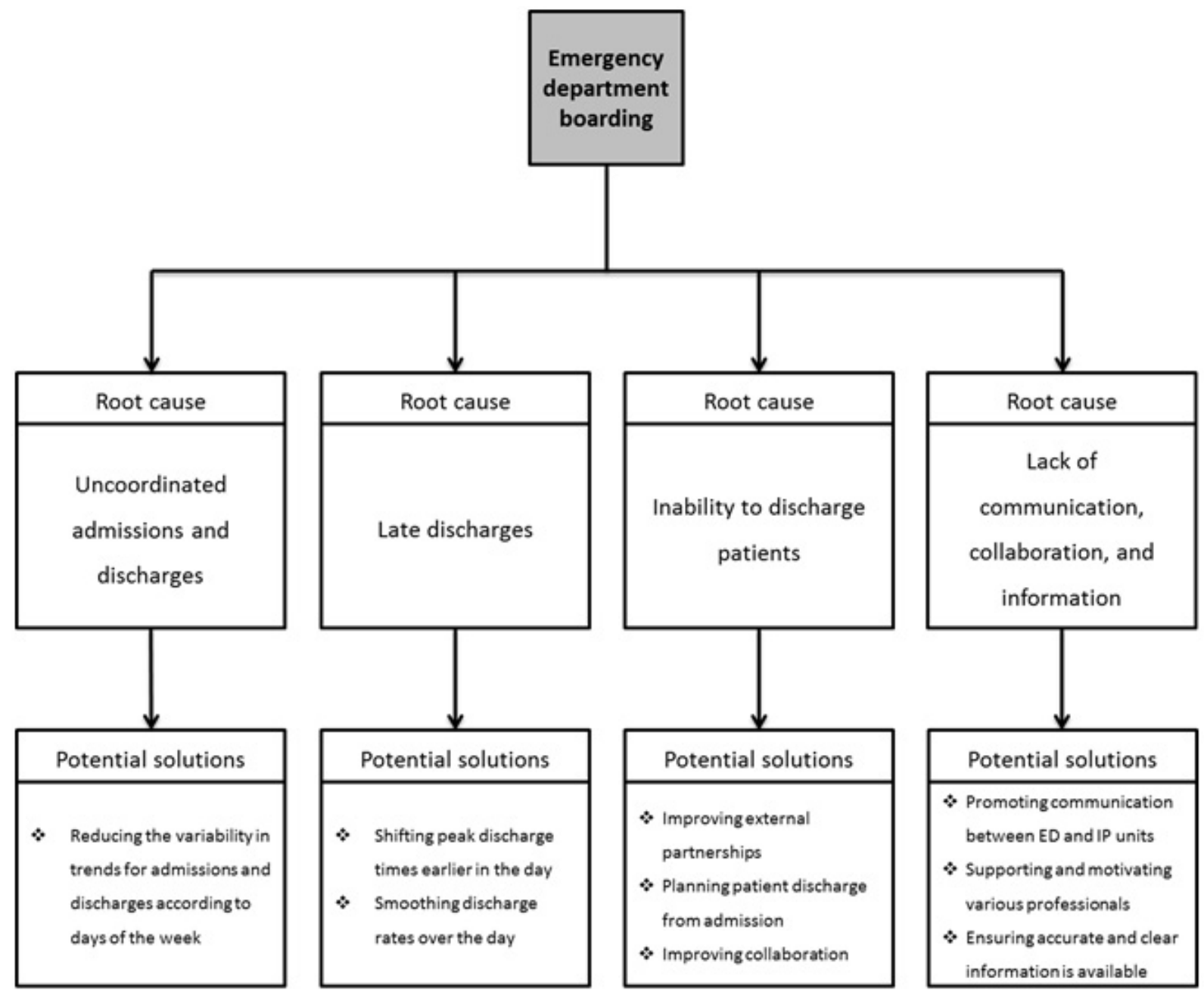

Figure 21. Final conceptual framework displaying the 4 root causes of ED boarding and their potential solutions

Since the qualitative categories were created by the authors, and the data collected from the qualitative interviews was interpreted and categorized by the author as well, the nature of the data has a certain innate bias. Other researchers may have categorized the answers differently, or created categories that were more, or less, precise.

One of the most important limitations of this research is that not all of the actors within the patient care process were represented in the qualitative interviews. Moreover, there were a limited number of interviews conducted, and a limited amount of time possible for each interview, given that they were conducted during the interviewees' shifts.

A final limitation is related to the quantitative data obtained. There is a great deal of variability found in the boarding time 104 experienced by patients. Some are boarded for as little as 0 minutes, while others are boarded for as long as 12,000 minutes. Since there is a degree of human intervention within this process, perhaps the 0 minutes that are demonstrated in the statistics are not representative of reality. Nevertheless, outlying results such as these were scarce, and thus had very little impact on the overall analysis.

\section{Conclusions}

Through the analysis of various types of data, this study was able to pinpoint key issues causing ED boarding in three Canadian hospitals. Using this information, a final integrative conceptual framework for ED boarding was elaborated, which offers perspective for other hospitals and management 
practitioners as to what may be causing this issue within their own institutions. Rather than starting from scratch, these practitioners now have a framework demonstrating probable causes for ED boarding, which provides a starting point for analysis within their establishments. The framework further shows that the combination of quantitative and qualitative data is very useful in understanding ED boarding time. The quantative data cannot only be used in the analysis stage, but can also help in designing a solution as there are clear recognizable trends (e.g. peaks). Moreover, if the root causes are seen to be significant in other institutions, pathways to

\section{REFERENCES}

[1] White BA, Biddinger PD, Yuchiao C, et al. 29 Boarding Inpatients in the Emergency Department Increases Discharged Patient Length of Stay. Journal of Emergency Medicine. 2013; 44(1): 230. PMid: 22766404. https://doi.org/10.1016/j.jemermed. 2012.05 .007

[2] Pitts SR, Vaughns FL, Gautreau MA, et al. A cross-sectional study of emergency department boarding practices in the United States. Academic Emergency Medicine Official Journal of the Society for Academic Emergency Medicine. 2014; 21(5): 497-503. PMid: 24842499. https://doi.org/10.1111/acem.12375

[3] Richards JR, Ozery G, Notash M, et al. Patients Prefer Boarding in Inpatient Hallways: Correlation with the National Emergency Department Overcrowding Score. Emergency Medicine International. 2010; 2011(1): 840459.

[4] Schull MJ, Redelmeier DA. Urban emergency department overcrowding: defining the problem and elimiating misconceptions. Canadian Journal of Emergency Medicine. 2002; 4: 76-83. PMid: 17612424. https://doi.org/10.1017/S1481803500006163

[5] Moskop JC, Sklar DP, Geiderman JM, et al. Emergency department crowding, part 1-concept, causes, and moral consequences. Annals of Emergency Medicine. 2009; 53(5): 605. PMid: 19027193. https://doi.org/10.1016/j. annemergmed.2008.09.019

[6] Asplin BR, Magid DJ, Rhodes KV, et al. A conceptual model of emergency department crowding. Annals of Emergency Medicine. 2003; 42(2): 173-180. PMid: 12883504. https://doi.org/10.1 067/mem.2003.302

[7] Walsh P, Cortez V, Bhakta H. Patients would prefer ward to emergency department boarding while awaiting an inpatient bed. Journal of Emergency Medicine. 2008; 34: 221-226. PMid: 17976825. https://doi.org/10.1016/j.jemermed.2007.05.012

[8] Bekmezian A, Fee C, Bekmezian S, et al. Emergency Department Crowding and Younger Age are Associated with Delayed Corticosteroid Administration to Children with Acute Asthma. Pediatric emergency care. 2013; 29(10): 1075. PMid: 24076611. https: //doi.org/10.1097/PEC.0b013e3182a5cbde

[9] Watts H, Nasim MU, Sweis R, et al. Further characterization of the influence of crowding on medication errors. Journal of Emergencies Trauma \& Shock. 2013; 6(4): 264. PMid: 24339659. https://doi.org/10.4103/0974-2700.120370

[10] Hong KJ, Shin SD, Song KJ, et al. Association between ED crowding and delay in resuscitation effort. American Journal of Emer- improvement are demonstrated as well, which will help managers to reduce ED boarding. The methods by which the hospital communicates with its employees, the methods by which employees communicate together, and the nature of collaborative efforts should not be underestimated in these improvement efforts. Understanding the nature of these interpersonal problems is an important step in improving this ED boarding problem and is at the same time an important topic for further research.

\section{CONFLICTS OF INTEREST Disclosure}

The authors declare they have no conflict of interest. gency Medicine. 2013; 31(3): 509-515. PMid: 23159432. https: //doi.org/10.1016/j.ajem.2012.09.029

[11] Falvo T, Grove L, Stachura R, et al. The opportunity loss of boarding admitted patients in the emergency department. Academic Emergency Medicine Official Journal of the Society for Academic Emergency Medicine. 2007; 14(4): 332. PMid: 17331916. https: //doi.org/10.1111/j.1553-2712.2007.tb02017.x

[12] Chan SS, Cheung NK, Graham CA, et al. Strategies and solutions to alleviate access block and overcrowding in emergency departments. Hong Kong Academy of Medicine. 2015; 21(4): 345.

[13] Yin RK. Case Study Research: Design and Methods. Fourth ed. Applied Social Resarch Methods Series. California, United States: Sage Publications; 2009.

[14] Andersson G, Karlberg I. Lack of integration, and seasonal variations in demand explained performance problems and waiting times for patients at emergency departments: a 3 years evaluation of the shift of responsibility between primary and secondary care by closure of two acute hospitals. Health Policy. 2001; 55(3): 187-207. https://doi.org/10.1016/S0168-8510(00)00113-5

[15] McCarthy ML, Zeger SL, Ding R, et al. The Challenge of Predicting Demand for Emergency Department Services. Academic Emergency Medicine Official Journal of the Society for Academic Emergency Medicine. 2008; 15(4): 337. PMid: 18370987. https : //doi.org/10.1111/j.1553-2712.2008.00083.x

[16] Huang YL. Ancillary service impact on outpatient scheduling. International Journal of Health Care Quality Assurance. 2013; 26(8): 746-759. PMid: 24422263. https://doi .org/10.1108/IJHCQA -02-2012-0019

[17] Davis B, Sullivan S, Levine A, et al. Factors affecting ED length-ofstay in surgical critical care patients. American Journal of Emergency Medicine. 1995; 13(5): 495-500. http://dx.doi.org/10.1186 /1478-4505-9-20

[18] Nagula P, Lander R, Rivero R, et al. Use of continuous quality improvement tools to streamline the workflow of ancillary departments. IIE Annual Conference. 2006. PMid: 16274836.

[19] Hancock WM, Walter PF. The use of admissions simulation to stabilize ancillary workloads. Simulation. 1984; 43(2): 88-94. https: //doi.org/10.1177/003754978404300203

[20] Foster S. The key to solving the staffing crisis? British Journal of Nursing. 2014; 23(19). https://doi.org/10.12968/bjon.20 14.23.19.1053

[21] Hwang U, Richardson LD, Sonuyi TO, et al. The effect of emergency department crowding on the management of pain in older adults with 
hip fracture. Journal of the American Geriatrics Society. 2006; 54(2): 270-275. PMid: 16460378 . https://doi.org/10.1111/j.1532 $-5415.2005 .00587 . x$

[22] Ortiga B, Salazar A, Jovell A, et al. Standardizing admission and discharge processes to improve patient flow: A cross sectional study. BMC Health Services Research. 2012; 12(1): 1-6. PMid: 22741542. https://doi.org/10.1186/1472-6963-12-180

[23] Liu SW, Hamedani AG. Established and novel initiatives to reduce crowding in emergency departments. Western Journal of Emergency Medicine. 2013; 14(2): 85-89. PMid: 23599838. https: //doi.org/10.5811/westjem.2012.11.12171

[24] Mcconnell KJ, Richards CF, Daya M, et al. Effect of increased ICU capacity on emergency department length of stay and ambulance diversion. Annals of Emergency Medicine, 2005; 45(5): 471-478. PMid: 15855939. https://doi.org/10.1016/j. annemergmed . 2004.10 .032

[25] Mumma BE, Mccue JY, Li CS, et al. Effects of Emergency Department Expansion on Emergency Department Patient Flow. Academic Emergency Medicine Official Journal of the Society for Academic Emergency Medicine. 2014; 21(5): 504-9. PMid: 24842500. https://doi.org/10.1111/acem.12366

[26] Rathlev NK, Chessare J, Olshaker J, et al. Time Series Analysis of Variables Associated With Daily Mean Emergency Department Length of Stay. Annals of Emergency Medicine. 2007; 49(3): 265271. PMid: 17224203 . https ://doi.org/10.1016/j.annemerg med.2006.11.007

[27] Guerriero F, Guido R. Operational research in the management of the operating theatre: a survey. Health Care Management Science. 2011; 14(1): 89-114. PMid: 21103939. https://doi.org/10.1007/s1 0729-010-9143-6

[28] Powell ES, Khare RK, Venkatesh AK, et al. The relationship between inpatient discharge timing and emergency department boarding. Journal of Emergency Medicine. 2012; 42(2): 186. PMid: 20888163 https://doi.org/10.1016/j.jemermed . 2010.06.028

[29] Wertheimer B, Jacobs RE, Bailey M, et al. Discharge before noon: an achievable hospital goal. Journal of Hospital Medicine An Official Publication of the Society of Hospital Medicine. 2014; 9(4): 210. PMid: 24446232. https : //doi.org/10.1002/jhm. 2154

[30] Timbie JW, Ringel JS, Fox DS, et al. Systematic review of strategies to manage and allocate scarce resources during mass casualty events. Annals of Emergency Medicine. 2013; 61(6): 677-689. PMid:
23522610. https://doi.org/10.1016/j. annemergmed. 2013 .02 .005

[31] Knebel AR, Sharpe VA, Danis M, et al. Informing the gestalt: an ethical framework for allocating scarce federal public health and medical resources to states during disasters. Disaster Medicine and Public Health Preparedness. 2014; 8(1): 79-88. PMid: 24612854. https://doi.org/10.1017/dmp. 2014.9

[32] Rogowski WH, Grosse SD, Schmidtke J, et al. Criteria for fairly allocating scarce health-care resources to genetic tests: which matter most? European Journal of Human Genetics Ejhg. 2014; 22(1): 25-31. PMid: 23921536. https://doi .org/10.1038/ejhg. 201 3.172

[33] Costa AP, Poss JW, Thomas P, et al. Acute care inpatients with longterm delayed-discharge: evidence from a Canadian health region. BMC Health Services Research. 2012; 12(1): 172. PMid: 22726609. https://doi.org/10.1186/1472-6963-12-172

[34] Pirani SSA. Prevention of delay in the patient discharge process: an emphasis on nurses' role. Journal for Nurses in Staff Development. 2010; 26(4): 1-5. PMid: 20683293. https ://doi.org/10.1097/ NND. 0b013e3181b1ba74

[35] Challis D, Hughes J, Xie C, et al. An examination of factors influencing delayed discharge of older people from hospital. International Journal of Geriatric Psychiatry. 2014; 29(2): 160-8. PMid: 23661304 https://doi.org/10.1002/gps. 3983

[36] Leonard M, Graham S, Bonacum D. The human factor: the critical importance of effective teamwork and communication in providing safe care. Quality \& Safety in Health Care. 2004; 13 Suppl 1(1): 85-90.

[37] Hesselink G, Schoonhoven L, Plas M, et al. Quality and safety of hospital discharge: a study on experiences and perceptions of patients, relatives and care providers. International Journal for Quality in Health Care. 2012; 25(1): 66. PMid: 23184652. https: //doi.org/10.1093/intqhc/mzs066

[38] Helles $\varnothing$ R, Sogstad MK. Hospital nurses' and physicians' use of information sources during their production of discharge summaries: a cross-sectional study. Studies in Health Technology and Informatics. 2014; 201: 335-341. PMid: 24943564.

[39] Kannampallil TG, Jones LK, Patel VL, et al. Comparing the information seeking strategies of residents, nurse practitioners, and physician assistants in critical care settings. Journal of the American Medical Informatics Association. 2014; 21(E2): 249-56. PMid: 24619926. https://doi.org/10.1136/amiajnl-2013-002615 